Portland State University

PDXScholar

Dissertations and Theses

Dissertations and Theses

Summer 9-3-2015

\title{
Neurobiology of Seasonal Life-history Transitions
}

Ashley Rae Lucas

Portland State University

Follow this and additional works at: https://pdxscholar.library.pdx.edu/open_access_etds

Part of the Biology Commons, and the Neuroscience and Neurobiology Commons Let us know how access to this document benefits you.

\section{Recommended Citation}

Lucas, Ashley Rae, "Neurobiology of Seasonal Life-history Transitions" (2015). Dissertations and Theses. Paper 2511.

https://doi.org/10.15760/etd.2508

This Thesis is brought to you for free and open access. It has been accepted for inclusion in Dissertations and Theses by an authorized administrator of PDXScholar. Please contact us if we can make this document more accessible: pdxscholar@pdx.edu. 
Neurobiology of Seasonal Life-history Transitions

\author{
by
}

Ashley Rae Lucas

A thesis submitted in partial fulfillment of the requirements for the degree of

Master of Science

in

Biology

Thesis Committee:

Deborah I. Lutterschmidt, Chair

Randy D. Zelick

Michael T. Murphy

\title{
Portland State University
}

2015 
(C) 2015 Ashley Rae Lucas 


\begin{abstract}
Many animals exhibit seasonal changes in life-history stages, and these seasonal transitions are often accompanied by dramatic switches in behavior. While the neuroendocrine mechanisms that regulate such behavioral transitions are poorly understood, arginine vasotocin (AVT) and neuropeptide Y (NPY) are excellent candidates because they regulate reproductive and feeding behavior, respectively. In this study, I asked if seasonal changes in AVT and/or NPY are concomitant with spring migration away from the breeding grounds, as male and female red-sided garter snakes (Thamnophis sirtalis parietalis) are transitioning from reproductive to non-reproductive behavior during this time. To address this question, I collected male and female snakes in different migratory stages during the spring and fall. Brains were processed for AVT and NPY immunohistochemistry and the total number of immunoreactive (-ir) cells quantified for each individual. As predicted, males had significantly more AVT-ir cells in the preoptic area and bed nucleus of the stria terminalis, brain regions important for courtship behavior, during the spring mating season compared to the fall. Females had significantly more AVT-ir cells in the preoptic area during the spring compared to the fall and, surprisingly, did not exhibit seasonal changes in NPY. In contrast, males had significantly more NPY-ir cells in the cortex, a region important for spatial memory, and in the posterior hypothalamus during the fall compared to the spring, which likely reflects increased feeding behavior during the summer foraging period. Neither AVT- nor NPY-ir cell number varied significantly with migratory status, indicating that seasonal changes in these neuropeptides are not directly related to migration. I then asked if the observed
\end{abstract}


seasonal changes in AVT and NPY in males and females are related to the transition from reproductive to non-reproductive states. Compared to courting males, non-courting males had significantly more AVT-ir cells in the supraoptic nucleus and more NPY-ir cells in the cortex. AVT- and NPY-ir cells did not differ between unmated and mated females. Collectively, my results suggest that AVT and NPY play a role in regulating seasonal transitions in male reproductive behavior, rather than regulating migration per se. Further, these data indicate that both AVT and NPY are regulating reproductive behavior differently in males versus females. These data provide the framework for future studies examining the mechanisms regulating transitions between reproductive, migratory and foraging behaviors. 


\section{Dedication}

I would like to dedicate this work to my friends and family who supported me throughout this project. And to my wonderful husband without whom I would not have survived graduate school. 


\section{Acknowledgements}

I thank the Manitoba Department of Conservation and Dave Roberts for logistical support in Manitoba, Canada. I thank Catherine Dayger, Chris Friesen, and Robert Mason for technical assistance. Partial funding for this work was provided by the National Science Foundation, Portland State University Faculty Enhancement Grant, and Oregon Health and Science University Medical Research Foundation Grant to D.I.L. and Portland State University Forbes/Lea Scholarship to A.R.L. 


\section{Table of Contents}

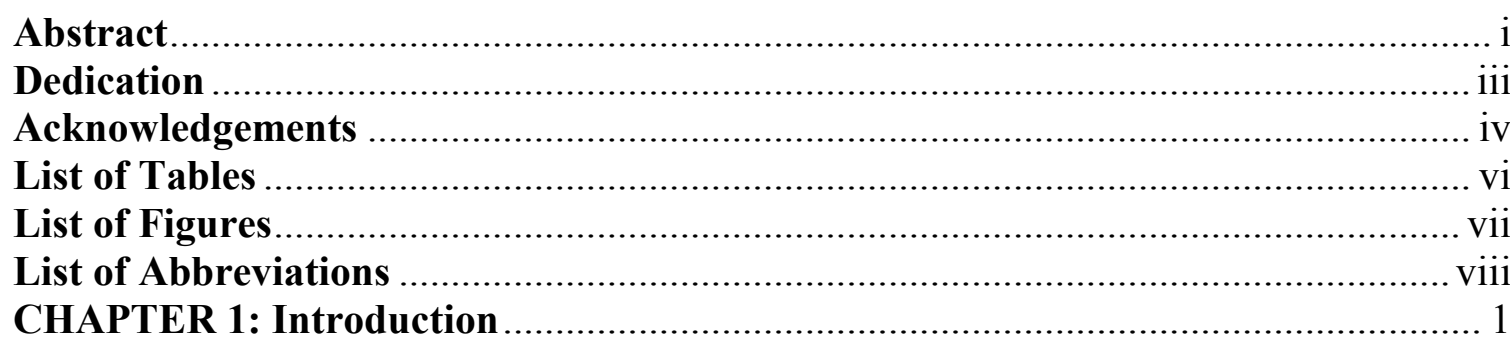

Life-history Stages and Transitions

Synchronization of Seasonal Life-history Stages

Sex Differences in Life-history Stage Transitions

Neuropeptides as a Mechanism of Behavioral Transitions

Study System

Questions and Hypotheses

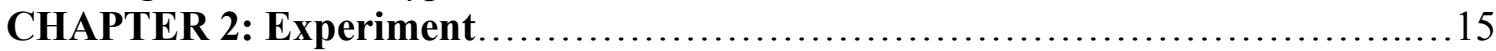

Introduction

Materials and Methods

Results

Discussion

CHAPTER 3: Conclusions and Future Directions..............................56

Seasonal Differences

Sex Differences

Changes in Migratory Status

Changes in Reproductive Status

Comparisons between Thamnophis Populations

Conclusions

References 


\section{List of Tables}

Table 1: Initial collection sample sizes for each experiment for male and female red-sided

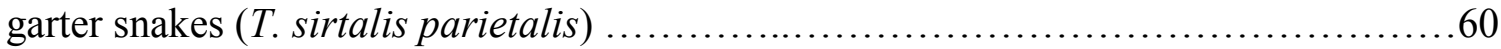




\section{List of Figures}

Figure 1: Effects of season and migratory status on the total number of AVT-ir cells of male and female red-sided garter snakes (T. sirtalis parietalis) $\ldots \ldots \ldots \ldots \ldots \ldots \ldots \ldots \ldots 61$

Figure 2: Effects of season and migratory status on the total number of NPY-ir of male

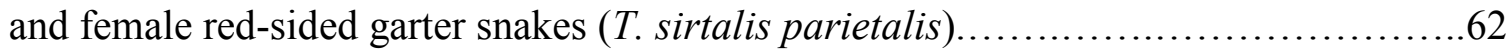
Figure 3: Relationship between the number of AVT-ir cells within the POA and plasma estradiol and plasma corticosterone concentrations within female red-sided garter snakes

(T. sirtalis parietalis).

Figure 4: Effects of reproductive status on the total number of AVT-ir cells in male and female red-sided garter snakes (T. sirtalis parietalis). .64

Figure 5: Effects of reproductive status on the total number of NPY-ir cells in males from the feeding grounds and females from the den red-sided garter snakes (T. sirtalis

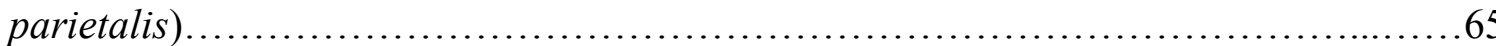




\section{List of Abbreviations}

$\begin{array}{ll}\text { AH } & \text { anterior hypothalamus } \\ \text { ANOVA } & \text { analysis of variance } \\ \text { AVP } & \text { arginine vasopressin } \\ \text { AVT } & \text { arginine vasotocin } \\ \text { BNST } & \text { bed nucleus of the stria terminalis } \\ \text { BrdU } & \text { 5-bromo-2'deoxyuridine } \\ \text { DMN } & \text { dorsomedial hypothalamic nucleus } \\ \text { LHA } & \text { lateral posterior hypothalamic nucleus } \\ \text { NS } & \text { nucleus sphericus } \\ \text { NPY } & \text { neuropeptide Y } \\ \text { PH } & \text { posterior hypothalamus } \\ \text { POA } & \text { preoptic area } \\ \text { PVN } & \text { periventricular hypothalamic nucleus } \\ \text { SON } & \text { supraoptic nucleus } \\ \text { SMN } & \text { ventromedial hypothalamic nucleus } \\ \text { PMent length }\end{array}$




\section{CHAPTER 1: Introduction}

\section{Life-history Stages and Transitions}

A life-history stage is characterized by a set of distinct behaviors, morphologies, or physiologies associated with a single life event. These life-history stages can include breeding, mating, migration and hibernation cycles (Wada, 2008). In some animals, lifehistory stages are incompatible with one another. For example, mating behaviors are not usually expressed simultaneously while an animal forages, so animals must transition from one set of physiologies and behaviors to another. Thus, a life-history transition can be broadly defined as a transition from one physiological or behavioral state to another. Some species exhibit cycles of behaviors yearly, seasonally, or within a single season and each stage of this cycle can be recognized by the specific behaviors exhibited by an animal during that stage. For example, animals in reproductive states exhibit mating behaviors like courtship or mounting.

Transitions from one life-history stage to another often occur between seasons (Wingfield, 2008; Wingfield et al., 1998). For example, grizzly bears (Ursus arctos) are hyperphagic during the autumn and hypophagic during winter hibernation (Bryan, 2013). Success during an individual bear's feeding season is critical to future success during energetically costly events such as reproduction (Bryan, 2013). Additionally, anadromous fish like the Atlantic salmon (Salmo salar) have distinct life-history stages within a single year and among years. Atlantic salmon spawn during the autumn or winter and is partially characterized by reduced feeding behavior. After spawning, some individuals 
will either return to the sea or wait until the spring to resume feeding (Jonsson and Jonsson, 2009; Jonsson et al., 1990; McBride et al., 1965). Each of these stages, and associated behaviors, can influence success at the next stage, or carry-over effects. For example, the quality of overwintering location for American Redstart influences the date of migration, resources available to fuel reproduction and eventual reproductive success (Reudink et al., 2009).

Life-history transitions are often linked with migratory or dispersal events that allows an animal to utilize different geographic resources during specific life-history stages. Because motivation for specific resources change, animals often disperse to new locales with new resources during life-history transitions. For example, male Puget Sound white-crowned sparrows (Zonotrichia leucophrys pugetensis) migrate to spring breeding grounds and exhibit courtship behavior to attract and copulate with female sparrows. During spring migration, this species undergoes a transition period between regressed gonads in the winter and reactivation and development of gonads for the spring breeding season (Wingfield et al., 1998; Wingfield and Farner, 1978). However, the mechanisms that regulate these life-history transitions are poorly understood. We know some of the mechanisms that regulate behaviors within a single life-history stage (e.g., courtship behavior during the mating season), but how behaviors change from one-toanother during migration is not yet understood. 


\section{Synchronization of Seasonal Life-history Stages}

Many animals must synchronize behaviors with optimal environmental conditions, and often there is a temporal separation between behaviors. With respect to temporal separation, reproductive and foraging behaviors are sometimes not exhibited during the same time period and critically must be synchronized with optimal environmental conditions. Indeed, North American elk (Cervus elaphus nelsoni) copulate and fertilize eggs in the fall such that that parturition coincides appropriately with a nutrient flush that occurs during the late spring/ early summer (Powers et al., 2011). Additionally, grizzly bears have a distinct feeding season that coincides with an influx of spawning salmon at the bears' feeding grounds (Wilson, 1993). This provides an appropriate and abundant fuel reserve for bear survival during winter hibernation. Not only does the onset of specific behaviors need to be synchronized, but variations in individual behavior types need to be synchronized to a specific life-history stage. For example, some animals have evolved different feeding tactics for each food type that becomes available during that life-history stage. Dunlins (Calidris alpina) utilize different foraging strategies during different seasons to aid in prey capture of different types. During spring migration, there is an abundance of worms, bivalve siphons and shrimp that are captured by dunlins using a visual foraging strategy, but during winter they shift to a probing strategy that is more effective when food is less abundant and directed mostly at small buried bivalves (Martins et al., 2013). The different feeding strategies utilized by dunlins must coincide with the location and time of availability of food items. 
Synchronization ensures that the timing of reoccurring life-history transitions coincides with opportunities to mate and eat. If the timing of a life-history transition and associated behaviors are not timed correctly, then the individual can suffer consequences that impact fuel acquisition and ultimately decrease reproductive fitness. Mistiming has been demonstrated in Atlantic salmon embryos. Skoglund et al. (2011) incubated Atlantic salmon embryos at different temperatures, which resulted in different hatching times. The embryos that were incubated at temperatures below that of controls hatched later, had lower body mass, and decreased survival. The authors attributed this decreased survival to higher stream densities of fish that had emerged earlier and consumed a majority of the resources, leaving the late hatching fish with fewer resources (Skoglund et al., 2011). Similarly, Peary caribou (Rangifer tarandus pearyi) exhibit different calving times than availability of food resources because plant-growing seasons are altered by climate change (Post and Forchhammer, 2008), which is impacting fitness.

There is a need to understand how behaviors are regulated, so that we may understand how the timing of transitions are regulated. Transitions in behavior are often driven by a particular environmental factors the animal experiences, for example, resource availability. Knowledge of these mechanisms will allow us to better predict how populations will respond to climate change (Ball and Ketterson, 2008). For example, egg laying time in great tits (Parus major) over a 23 period has slowly advanced in response to increased environmental temperatures, but the peak in abundance of the great tit's major food item (i.e., caterpillars) has not advanced as rapidly. This has resulted in a mismatch between peak food demand of young and peak food abundance (Visser et al. 
(2006, 1998), and underscores the importance of understanding the mechanisms of behavior transitions to better understand how an organism responds to environmental cues. In the above case, great tits and caterpillars responded to the same environmental cue by either advancing or delaying, respectively, life-history stage.

\section{Sex Differences of Life-history Transitions}

The regulation of life-history transitions plays a significant role in the behavior that an animal should and/or will exhibit. It has been demonstrated numerous times in various species that there are seasonal differences in behaviors (see above). However, there are also differences between ages and sexes within species during a single lifehistory stage. For example, males may need more energy during the mating season, whereas females will need more energy to fuel pregnancy following the mating season. Males and females can migrate at different times, with mismatched deactivation of specific behaviors during migration. For example, female Syrian hamsters (Mesocricetus auratus) cease mating behavior prior to male hamsters. Sex differences in behavioral responses to hormones are also evident after gonadectomy in a laboratory setting. Receptivity behavior of female rats (Rattus sp.) declines within hours after ovariectomy, whereas male rats will continue to copulate for weeks after gonadal hormones are removed from circulation (Beery, 2007; Moreines and Powers, 1977). Additionally, males often initiate mating behavior or arrive at breeding grounds prior to females. Female greater sage grouse (Centrocerus urophasiamus) arrive after male grouse form a lek (Boyko et al., 2004), and many migratory birds, including female Puget Sound white- 
crowned sparrows and Eastern Kingbirds (Zonotrichia leucophrys pugetensis and Tyrannus tyrannus, respectively), arrive after male sparrows at the spring breeding grounds following migration (Cooper et al., 2009; Wingfield and Farner, 1978). Similarly, female red-sided garter snakes (Thamnophis sirtalis parietalis) emerge from winter hibernacula, copulate and disperse from the hibernaculum to feeding grounds (usually within 1 day of emergence), whereas male snakes spend several weeks at the hibernaculum searching for more courtship opportunities prior to dispersal (Shine et al., 2001; Moreines and Powers, 1977). The mechanism regulating such sex differences in the timing of life-history transitions is unknown.

Additionally, when males and females do not respond to stimuli in the same way, life-history events can become desynchronized within a species. European starlings (Sturnus vulgaris) that experienced an increase in temperature during the breeding season compared to previous years had a shortened breeding season. Male starlings had earlier testicular regression than control starlings, while female starlings remained reproductively active. Further studies are needed to understand the mechanisms of these sex differences in timing of physiological, hormonal and behavioral events (Dawson, 2005). Neuroendocrine studies are one of the key research areas for gaining a better understanding of these life-history transitions (Wingfield, 2008).

Neuropeptides as a Mechanism of Behavioral Transitions

Despite the importance of life-history transitions to both individual survival and reproductive success, we know very little about the physiological mechanisms mediating 
such transitions. For example, there are many hormones and neuropeptides that regulate feeding behavior as well as reproductive behavior (Schneider et al., 2013). However, how these factors interact to regulate transitions from courtship to feeding behavior under natural conditions are poorly understood. Neuropeptides are defined as a protein hormone produced by a neuron (Burbach, 2011), and are a likely mechanism regulating life-history transitions. Neuropeptide systems control motivational behavior as well as the prioritization of behaviors based on both internal cues (e.g., body fat content) and environmental stimuli (e.g., mate- or food- availability) (Schneider et al., 2013). Two neuropeptides that have an evolutionarily well conserved function, and are important to reproductive and feeding behavior are arginine vasotocin and neuropeptide Y.

The nonapeptide arginine vasotocin (AVT) and its mammalian homologue, arginine vasopressin (AVP), play a critical role in mediating reproductive behaviors and are known to have context-dependent effects (Wilczynski et al., 2005; Goodson and Bass, 2001). For example, AVT/AVP are associated with seasonal variation and sex differences in courtship and social behavior (Madison et al., 2008; Goodson, 2005; Toyoda et al., 2003; Tito et al., 1999; Boyd, 1994, 1991). More than any other class of neuropeptide, these homologues are the axis of social and reproductive behavioral plasticity, and AVT/AVP neuron locations are highly conserved throughout vertebrates (Goodson, 2005; Lim et al., 2004; Goodson and Bass, 2001; Foran and Bass, 1999; De Vries and Boyle, 1998). Moreover, many AVT injection studies (intraperitoneal [IP] and intracerebroventricular [ICV]) have demonstrated that AVT induces behavior effects via a dose-response, and at higher doses, reduced effects of AVT can be observed (Madison 
et al., 2008; Tachibana et al., 2004; Salek et al., 2002; Boyd, 1991; Caldwell et al., 1986). The effects of AVT on social and sexual behavior also varies among species (Wilczynski et al., 2005; reviewed by Goodson and Bass, 2001). Mendonça (2013) examined differences in cleaning behavior between Indo-Pacific bluestreak cleaner wrasse (Labroides dimidiatus) and corallivore wrasse (Labrichthys unilineatus), which do not exhibit cleaning behavior. Cleaning mutualistic behavior is exhibited by wrasse as (1) an approach to 'client' reef fish, and (2) followed by tactile cleaning of the 'client' fish. The cleaner wrasse had lower AVT-immunoreactive (ir) cell number and smaller cell size when compared to corallivore wrasse. An intramuscular injection of AVT into cleaner wrasse decreased cleaning behavior and approaches to 'client' reef fish, providing evidence that AVT regulates social behavior (Soares, et al., 2012). AVT-ir cell number did not vary between sexes in either of the two species, suggesting that AVT does not regulate sex-differences in these two wrasse species (Mendonça, et al., 2013), but these results could be due to a small sample size.

AVT is known to increase reproductive behavior in numerous species. In male white perch (Morone Americana), courtship behavior increased after ICV AVT when compared to IP injection (Salek et al., 2002). Additionally, ICV and IP AVT treatment increased courtship behavior in male red-bellied newts (Cynops pyrrhogaster), and in male and female bullfrogs (Rana catesbeiana), which exhibit sex-specific behaviors in response to injection (Toyoda et al., 2003; Boyd, 1994). Exogenous AVT stimulates oviposition and parturition time in female eastern fence lizards (Sceloporus undulates) (Guillette et al., 1990). The increases in reproductive behavior in response to AVT are 
observed in different motor pathways (e.g., clasping and calling behavior). An ICV injection of AVT increases amplexis in rough-skinned newts (Taricha granulosa), while antagonists reduce amplectic clasping behavior (Moore and Miller, 1983). In male cricket frogs (Acris crepitans), IP AVT increased the probability of reproductive calling behavior. After AVT was injected, call characteristics were associated with less aggressive calls, which were more attractive to female cricket frogs than those of salineinjected male frogs (Marler, et al., 1995). Additionally, in all these studies, the researchers observed a greater sensitivity to AVT (and lower dose needed) using ICV treatment compared to IP. These studies support a role for AVT as an important neuromodulator (Salek et al., 2002; Boyd, 1994; Le Mevel et al., 1991; Moore and Miller, 1983). Many studies have addressed AVT as an important mediator of reproductive and social behavior, and have addressed sex differences in behavior and AVT-ir cell number. However, few studies have examined the role of AVT in life-history transitions under natural field conditions (Salek et al., 2002). Specifically, does AVT activate or deactivate reproductive behavior during a life-history transition to a new suite of behaviors?

In contrast, Neuropeptide Y (NPY) is one of the most abundant neuropeptides in the central and peripheral nervous systems (Malva, et al., 2012). NPY was discovered in 1982 as part of a family of three peptides: NPY which is only found in neurons; peptide YY which is found in both neurons and endocrine cells; and pancreatic polypeptide which is found mainly in the endocrine pancreas. The two latter peptides are gut hormones (Gehlert, 2004; Tatemoto et al., 1982). NPY is a neuromodulatory peptide that 
regulates appetite and feeding behavior in all vertebrates studied, including red-sided garter snakes (Maniam and Morris, 2012; Morris and Crews, 1990). NPY increases both appetitive (e.g., motivation for food and food-seeking behavior) and consummatory (e.g., food intake/ ingestive) feeding behaviors (Schneider et al., 2013; Mercer et al., 2011; Morris and Crews, 1990). These appetitive and consummatory feeding behaviors increase after injection of NPY into the brain ventricles of rats, musk shrews (Suncus murinus), bullfrog larvae, red-sided garter snakes and goldfish (Carassius auratus) (Shimizu et al., 2013; Matsuda K, 2009; Bojkowska K, 2008; Heinrichs SC, 1992; Egawa M, 1990; Morris and Crews, 1990). Additionally, an NPY antagonist decreased food intake compared to vehicle-treated bullfrog larvae, immature rainbow trout (Oncorhynchus mykiss), and zebrafish (Danio rerio), and NPY receptor agonist increased feeding behavior (Shimizu et al., 2013; Yokobori et al., 2012; Aldegunde and Mancebo, 2006). The effects of NPY injection on feeding behavior in male rats, bullfrog larvae, and immature rainbow trout is dose-dependent (Shimizu et al., 2013; Aldegunde and Mancebo, 2006; Sahu, 2002; Levine and Morley, 1984; Egawa M, 1990). However,, Morris and Crews (1990) observed an increase in feeding behavior with both high and low doses of exogenous NPY and the high dose did not maintain increased feeding behavior after 24 hours. Not only does exogenous treatment of NPY have a U-shaped dose response, but mRNA expression and/or changes in brain NPY-immunoreactivity cell number are observed when consummatory behavior is expressed. Fasted female rats and zebrafish showed significantly more NPY-immunoreactive cells in the brain when compared to control animals (Yokobori et al., 2012; Kovács et al., 2007). Furthermore, qualitative observations of NPY-like immunoreactivity in male and female Iberian wall 
lizards (Podarcris hispanica), revealed seasonal differences of reproductive activity as well as regional differences in NPY-like immunoreactive neurons among brain regions (Salom et al., 1994). Fasted bullfrog larvae and winter flounder (Pseudopleuronectes americanus) had higher NPY mRNA expression than those fed normally (MacDonald and Volkoff, 2009; Shimizu et al., 2013). In contrast, fasted male and female cunner (Tautogolabrus adspersus), had lower NPY mRNA expression compared to fed cunner (Babichuk and Volkoff, 2013). Collectively, these studies demonstrate the effects of NPY on consummatory behavior by injection, agonist treatment, mRNA and protein expression within numerous species.

NPY injection has also revealed an inhibitory effect on courtship behavior in redsided garter snakes (T. sirtalis parietalis) and many rodents (Corp et al., 2001; Clark et al., 1997; Morris and Crews, 1990) and anxiety-like behavior in rodents. For example, Heilig and Murison (1987) injected NPY into male albino rats (Rattus sp.) and found increased field-activity, which is ordinarily a high-stress environment for rodents but also a method for studying habituation with a novel stimulus. These results suggest that NPY is important for increased social behavior as well as coping with stressful situations, both of which interact with motivation for feeding behavior. Furthermore, Morris and Crews (1990) suggest that NPY may be involved in the transition from sexual behavior to feeding behavior in many vertebrates.

As discussed above, there has been an abundance of research examining how both AVT and NPY regulate reproductive and feeding behaviors independently. However, we lack an understanding of how these neuropeptides regulate behavioral transitions, 
specifically from reproductive to non-reproductive stages. Furthermore, because internal and external cues play an important role in mediating behavioral transitions, there is a need to study how behaviors are regulated by neuropeptides during different life-history transitions. Specifically, how do neuropeptides regulate behavioral transitions during migration between seasons and sexes. I asked these questions to gain an understanding of the how AVT and NPY change between seasons, sexes, and during life-history stage transitions within red-sided garter snakes.

\section{Study System}

Red-sided garter snakes have an intense spring mating season lasting approximately one month, after which snakes disperse up to $18 \mathrm{~km}$ to summer feeding grounds (Gregory, 1977). Females transition from mating to dispersal and feeding behavior soon after emergence from their communal hibernaculum, whereas males remain near the hibernaculum for several weeks, searching for emerging females. Importantly, males do not eat during the mating season (Gregory, 1977). This lack of feeding behavior does not result from an absence of food items, as males actively choose courtship over feeding opportunities during the mating season (O'Donnell, et al., 2004). These data suggest that the life-history transition from mating to feeding behavior is regulated by an endogenous factor. Once snakes disperse, they do not return to the hibernaculum for further courtship opportunities (Shine et al., 2001). Snakes migrate to their summer feeding grounds, where they remain for 3 months. After the feeding season, snakes migrate back to the hibernaculum (Gregory, 1977). The well-characterized and 
sexually dimorphic timing of these life-history transitions, as well as distinct behaviors associated with each stage in $T$. sirtalis parietalis make it an excellent model organism to address my research questions.

Questions and Hypotheses

In chapter two, I will examine if there are seasonal differences in AVT- or NPYimmunoreactive cell number between the spring and fall dispersal periods within male and female red-sided garter snakes. I will use immunohistochemistry to label arginine vasotocin (AVT), an important peptide for reproductive behavior, and neuropeptide $\mathrm{Y}$ (NPY), an important peptide for the regulation of feeding behavior. These immunoreactive labeled cells provide a marker for examining neurons that are producing sufficient amounts of protein that can be detected by the assay. Note that, because of the threshold of detection, it is unlikely we are detecting NPY bound to receptors that are to be internalized at the synaptic cleft. I will address the following research questions within chapter two:

\section{1) Are there seasonal differences in AVT and NPY? I hypothesize that snakes} returning from feeding grounds during the fall will have more NPY cells compared to courting snakes collected during the spring. Furthermore, I hypothesize that courting snakes collected during the spring mating season will have more AVT cells compared to non-courting snakes collected during the fall.

2) Are there sex differences in the timing of changes in AVT and NPY? I hypothesize that females will exhibit changes in AVT and NPY compared to males because they likely 
emerge from the den "primed" for dispersal because they disperse to summer feeding grounds before males.

\section{3) Do AVT and NPY cell number change during the transition to migration or}

reproduction? Within males, I hypothesize that AVT cell number will be higher and NPY cell number lower in courting males compared to non-courting males. I hypothesize that AVT and NPY cell number will be higher in mated females compared to unmated females, because mated females are closer to migrating away from the den and activation of feeding behavior but have not suppressed mating behavior. Furthermore, I hypothesize that AVT cell number will be higher and NPY cell number will be lower in pre-migratory snakes compared to migrating snakes.

These data could transform the existing paradigm of mechanisms underlying sex

differences in reproductive timing. Future studies could include different populations and species. Common garter snakes (T. sirtalis) extends across North America from north to south, and from east to west which provides within-species comparison of life-histories compatible with different environments. 


\section{CHAPTER 2: Experiment}

\section{Introduction}

Many vertebrates exhibit distinct life-history stages that are associated with specific physiological and behavioral functions. Examples of such life-history stages include reproduction, migration, and foraging (Wada, 2008). Critically, many animals transition from one life-history stage to another as resource availability changes. For example, to maximize reproductive success, organisms should exhibit reproductive physiology and behavior when conspecifics are in breeding condition. Likewise, the probability of individual survival is maximized if animals exhibit foraging and feeding behavior when food is abundant. For many seasonal organisms, resource availability relegates most life-history stages to a specific time of year, and therefore seasonal transitions between life-history stages are often accompanied by dramatic changes in both physiology and appetitive and consummatory behavior. The neuroendocrine mechanisms that regulate seasonal life-history transitions, however, are poorly understood, particularly those that occur within an ecologically relevant context (Wingfield, 2008).

Neuropeptides within specific brain regions likely play an important role in mediating seasonal life-history transitions, because they both modulate physiology and behavior (Burbach, 2011) and vary seasonally (reviewed in Wingfield, 2008). Two neuropeptides that are likely candidates for regulating seasonal transitions between reproduction and foraging are arginine vasopressin (AVT) and neuropeptide Y (NPY). AVT, and its mammalian homologue, arginine vasopressin (AVP), play a critical role in mediating reproductive behavior and are known to have context-dependent effects 
(Wilczynski et al., 2005; Goodson and Bass, 2001). For example, AVT/AVP cell number changes both seasonally and varies with sex in response to reproductive and social behaviors (e.g., Madison et al., 2008; reviewed by Goodson, 2005; Toyoda et al., 2003; Tito et al., 1999; Boyd, 1994, 1991). Treatment of male rough-skinned newts (Taricha granulosa) with exogenous AVT increases courtship behavior (Moore and Miller, 1983). Locations of neurons that produce AVT/AVP are also highly conserved throughout vertebrates (reviewed in Goodson, 2005; Lim et al., 2004; Goodson and Bass, 2001; Foran and Bass, 1999; De Vries and Boyle, 1998), making it a target peptide for understanding the general mechanisms of reproductive life-history transitions in vertebrates.

By contrast, NPY is a neuromodulatory peptide that regulates appetite and feeding behavior in all vertebrates studied (Maniam and Morris, 2012). As one of the most abundant neuropeptides in the central and peripheral nervous systems (Malva et al., 2012), NPY increases both appetitive (e.g., food-seeking) and consummatory (e.g., ingestive) feeding behavior (Schneider et al., 2013; Mercer et al., 2011; Morris and Crews, 1990). For example, Sahu et al. (1988) investigated the effects of food deprivation and ingestion on NPY-like peptide concentrations in six brain nuclei within adult male rats (Rattus norvegicus). Within the paraventricular nucleus, NPY increased in response to food deprivation and decreased following food intake. However, NPY-like concentrations in the medial preoptic area increased following food intake. Importantly, NPY not only affects food intake, but it also has an inhibitory effect on sexual behavior (e.g., Schneider et al., 2013; Morris and Crews, 1990). Indeed, Morris and Crews (1990) observed increased feeding behavior and decreased courtship behavior in male red-sided 
garter snakes treated with exogenous NPY. Thus, changes in NPY within specific brain regions likely play an important role in mediating trade-offs between reproduction and feeding.

Independently, there is an abundance of research examining how both AVT and NPY regulate reproductive and feeding behaviors, respectively (e.g., Maniam and Morris, 2012; Goodson and Bass, 2001). However, few studies have examined if and how these neuropeptides interact to regulate transitions between reproduction and feeding. Because these behavioral transitions usually occur on a short time scale (i.e., from minutes to hours) in many vertebrates, it is often difficult to disentangle the mechanisms regulating these distinct behaviors. In this context, organisms that exhibit seasonal transitions between temporally distinct life-history stages can be particularly informative for understanding the neuroendocrine mechanisms that regulate the underlying physiology and behavior in all vertebrates. Moreover, studies examining the neurobiology of seasonal life-history transitions provide much needed insight into how neuropeptides regulate ecologically-relevant behaviors in a natural environmental context.

In the present study, I asked if AVT and NPY correlate with the seasonal lifehistory transition from reproduction to migration and non-reproductive behavior in male and female red-sided garter snakes. Specifically, I investigated whether AVT and NPY immunoreactivity in the brain varies with season, sex, or life-history stage. With respect to sex, I asked if changes in AVT and NPY were associated with differences in the timing of migration between sexes. For example, during the spring, female snakes typically migrate to summer feeding grounds soon after emerging from the den, whereas males remain near the den for several weeks to court newly-emerging females (Shine et al., 
2001). Lastly, I asked if changes in AVT and NPY were associated with changes in lifehistory stage (i.e., transitions in migrating status versus reproductive condition).

To address these questions, I used a well-studied population of red-sided garter snakes located in Manitoba, Canada. Red-sided garter snakes have a life-history cycle that includes eight months of winter dormancy, after which snakes emerge from underground dens in late April to mid-May and engage in an intense, 4-wk mating period at the den. Males and females do not eat during both winter dormancy and the breeding season (Gregory and Stewart, 1975), but rather migrate to summer feeding grounds after emergence and attempting to mate. The factors that induce migration from the den site are not yet known, but previous observations suggested that it was not simply due to an increase in feeding behavior (personal observations). Following summer feeding, snakes migrate back to the den site in preparation for winter dormancy. Red-sided garter snakes are an ideal model system for this study because they exhibit seasonal transitions between the distinct life-history stages of hibernation, reproduction, migration and foraging. Furthermore, I could exploit naturally-occurring sex differences in the timing of these life-history transitions to better understand the role of AVT and NPY in mediating seasonal changes in behaviors.

\section{Materials and Methods}

These experiments were performed in the field with free-ranging red-sided garter snakes in the Interlake region of Manitoba, Canada. Experimental protocols were approved by the Portland State University Animal Care and Use Committee and were in compliance with guidelines established by the National Institutes of Health Guide for the 
Care and Use of Laboratory Animals. This research was performed under the authority of Wildlife Scientific Permit WB12691 issued by the Manitoba Department of Conservation.

Experimental Design

One important advantage of the red-sided garter snake system is that I could simultaneously collect snakes in different migratory states without introducing temporal variation into my measures of physiology and behavior. For example, during the spring I collected both pre-migratory snakes from the den and migrating snakes along the migratory route on the same day. Likewise, during the fall migration back to the den in preparation for winter dormancy, I collected migrating snakes from the migratory route and post-migratory snakes from the den on the same day. Similar to Cease et al. (2007), I used a road located approximately $0.9 \mathrm{~km}$ from the den along the migration route to aid in the collection of migrating snakes.

During the spring mating season, I also simultaneously collected snakes in different reproductive conditions. For example, at the den, females were collected both prior to and immediately after mating. By contrast, female snakes collected from the road typically had visible mating plug residue, indicating that they mated prior to migration from the breeding grounds. While virtually all males at the den exhibit courtship behavior, at least some male snakes collected from the road no longer express courtship behavior (personal observations). Thus, I used courtship trials as described by Lutterschmidt et al. (2004) to categorize the reproductive status of each male collected 
from the road during the spring as courting or non-courting. I used a well-established ethogram of male courtship behavior (Lutterschmidt et al., 2004; modified from Crews, 1984 and Moore et al., 2000) for these behavioral analyses. Of the 22 migrating males collected from the road during the spring, 10 male snakes exhibited courtship scores $\geq 3$, behaviors that are only expressed in the context of reproduction (Crews, 1984). These males were therefore classified as "courting" and included in Experiment 1, while the remaining 12 snakes were classified as "non-courting" and reserved for Experiment 2. Importantly, these migratory and behavioral phenotypes allow us to examine changes in brain neuropeptides related to migratory status separately from those changes related to seasonal transitions in reproductive behavior.

Experiment 1. Seasonal and Sex Variation in Brain AVT and NPY: Relation to Migratory Behavior

I first asked if there were seasonal or sex differences in AVT and NPY. To determine if these differences were related to changes in migratory behavior, I compared non-migratory snakes collected from the den to migratory snakes collected from the road in each season. During the spring, all migratory females collected from the road were presumed to have mated prior to dispersal (Shine et al., 2001). Thus, I compared migrating female snakes $(n=10)$ to mated females from the den $(n=11)$; females were collected from mating pairs and confirmed to be mated by the presence of a mating plug in the cloaca. Similarly, I compared migratory courting males $(n=10)$ collected from the road to pre-migratory courting males $(n=10)$ collected from the den. I therefore focused my question on the effect of migration on AVT and NPY without introducing the 
confounding variable of differences in female reproductive status (mated vs. unmated) or male reproductive behavior (courting vs. non-courting). All spring animals were collected from 14-18 May 2012, with equal numbers of pre-migratory and migratory snakes collected on each day.

During the fall, I compared migrating snakes collected from the road to postmigratory snakes collected from the den site. I collected 10 females and 10 males that had migrated to the road from the summer feeding grounds. I collected an additional 10 females and 10 males from the den during the fall pre-hibernation period, when snakes return to the den in preparation for winter dormancy. All fall animals were collected on 10 September 2012.

Experiment 2. Changes in Brain AVT and NPY during the Spring Mating Season:

\section{Relation to Reproductive Status}

During Experiment 1 , I noted that migratory males collected at the road exhibited two different behavioral phenotypes: some males continued to actively court females while others did not and were classified as non-courters. Differences in courtship behavior among migratory males has been described anecdotally (Lutterschmidt and Maine, 2014), but has not yet been investigated experimentally. I therefore asked if variation in AVT and NPY might be associated with the seasonal life-history transition from reproductive to non-reproductive status in both male and female snakes. To address this question, I needed to distinguish the changes in neuropeptides related to migration from those related to changes in reproductive behavior. I therefore focused on the differences between reproductive and non-reproductive snakes while keeping migratory 
status constant.

To examine changes in neuropeptides related to transitions in reproductive behavior, I compared AVT and NPY between the 10 courting males and 12 non-courting males collected from the road during the spring. To determine changes related to reproductive status in females, I collected an additional 10 females from the den immediately upon spring emergence and prior to mating. I then compared AVT and NPY between these unmated females and the 11 mated females collected from the den during Experiment 1 . I confirmed unmated status by verifying the absence of a mating plug in the cloaca. Table 1 summarizes sample sizes for Experiments 1 and 2 for comparisons of season, sex, migratory and reproductive status.

\section{Tissue Collection and Animal Handling}

Immediately upon capture, blood samples $(200 \mu 1)$ were collected within 3 min with tuberculin syringes and heparinized 25-gauge needles. Body mass and snout-vent length (SVL) were recorded for all snakes before they were scale clipped on the ventral scales with a unique number to identify individuals throughout these experiments. Snakes then received 2 intraperitoneal pulse injections of $100 \mathrm{mg}$ per $\mathrm{kg}$ of body mass 5-bromo2'-deoxyuridine (BrdU) as in Maine et al. (2014) and Almli and Wilczynski (2007). BrdU is a thymidine analog that is incorporated into the DNA of mitotic cells. I treated snakes with BrdU to examine whether seasonal changes in migratory and/or reproductive status were associated with variation in cell proliferation and cell migration within the brain. These data were the subject of additional analyses not presented here. 
Snakes were housed in semi-natural outdoor arenas $(1 \times 1 \times 1 \mathrm{~m})$ containing a hide box and water bowl. Four days after their initial capture, a second blood sample was collected from each individual before snakes were euthanized with a lethal overdose of $1 \%$ sodium pentobarbital $(0.2 \mathrm{ml} /$ snake $)$. During the spring, male courtship behavior was assessed prior to final tissue collection. I chose this sampling time because my prior studies demonstrated optimal labeling of newly proliferated cells within 4-5 days of BrdU treatment (Maine et al., 2014). Thus, this experimental design allowed me to minimize animal numbers while simultaneously assessing potential changes in neurogenesis, AVT, and NPY associated with seasonal changes in migratory and reproductive behaviors. My previous studies indicate that injection with BrdU did not alter reproductive behavior or brain neuropeptides in male red-sided garter snakes (Lutterschmidt, unpublished data; Maine, et al., 2014). Thus, it is unlikely that treatment of snakes w/ BrdU affected the results presented here.

Brains were immersion-fixed in 4\% paraformaldehyde in $0.1 \mathrm{M}$ phosphate buffer (pH 7.2) for $18 \mathrm{~h}$ at $4{ }^{\circ} \mathrm{C}$. Tissues were then transferred to $0.1 \mathrm{M}$ phosphate buffer and stored at $4{ }^{\circ} \mathrm{C}$ until transported to Portland State University for sectioning. Brains were cyroprotected in $30 \%$ sucrose in $0.1 \mathrm{M}$ phosphate buffer and cut on a cryostat (Leica $3050 \mathrm{~S}$ ) into four alternate series of $25-\mu \mathrm{m}$ coronal sections. Tissues were thaw-mounted onto subbed slides (Fisherbrand Superfrost Plus) and stored at $-20{ }^{\circ} \mathrm{C}$ until immunohistochemical processing. 


\section{Radioimmunoassay}

Blood samples were stored at $1{ }^{\circ} \mathrm{C}$ after collection until centrifuged and the plasma separated. Plasma was kept frozen at $-4{ }^{\circ} \mathrm{C}$ in the field or $-80{ }^{\circ} \mathrm{C}$ after transfer to Portland State University. Plasma samples were assayed for corticosterone, androgen and estradiol concentrations via direct radioimmunoassay following procedures described and validated for red-sided garter snakes by Lutterschmidt and Mason (2009, 2005). Corticosterone and androgen concentrations were determined from the same aliquot of male plasma; corticosterone and estradiol concentrations were determined from the same aliquot of female plasma. Each sample was incubated with tritiated steroid for individual sample recovery determination, which was calculated from an aliquot of extracted and reconstituted sample. The remaining sample was allocated to two duplicate culture tubes for each steroid hormone being assayed. All samples were incubated with 12,000 cpm 1,2,6,7- $\left[{ }^{3} \mathrm{H}\right]$ corticosterone, 1,2,6,7 - $\left[{ }^{3} \mathrm{H}\right]$ testosterone, or 2,4,6,7 - $\left[{ }^{3} \mathrm{H}\right]$ estradiol (items NET399250UC, NET370250UC, and NET317250UC, respectively; Perkin Elmer, Piscataway, NJ). All tubes except non-specific binding samples were also incubated with $100 \mu \mathrm{l}$ antiserum at $4{ }^{\circ} \mathrm{C}$ for $18-24 \mathrm{~h}$ (corticosterone antibody 07120016 from MP Biomedicals, LLC, Solon, OH; testosterone antibody 20R-TR018w and estradiol antibody 20R-ER012w from Fitzgerald Industries International, Acton, MA). Following separation of the bound fraction with dextran-coated charcoal, the radioactivity of each sample was quantified in a Beckman 6500 liquid scintillation counter.

My direct assay measured both plasma testosterone and 5- $\alpha$-dihydrotestosterone concentrations due to $63 \%$ crossreactivity of the testosterone antibody with 5- $\alpha$ - 
dihydrotestosterone (Fitzgerald Industries International). For these reasons, I present here data for total androgen concentrations. All hormone concentrations were corrected for individual recovery variation; mean extraction efficiency was $90.8 \%$. All samples were randomly distributed across multiple assays. Mean intra-assay coefficients of variation were $11.4 \%$ for corticosterone, $12.7 \%$ for androgens and $15.0 \%$ for estradiol. The interassay coefficient of variation was $17.9 \%$ for corticosterone, $14.8 \%$ for androgens and $16.7 \%$ for estradiol. Average limits of detectability were $32.8 \mathrm{pg} / \mathrm{ml}$ for corticosterone, $19.2 \mathrm{pg} / \mathrm{ml}$ for androgens and $8.4 \mathrm{pg} / \mathrm{ml}$ for estradiol. All plasma corticosterone concentrations were above the limits of detectability. When androgen and estradiol concentrations were below the limits of detection for an assay, I assigned those samples the limit of detectability to retain these individuals in my statistical analyses. This occurred in $1.2 \%$ of the androgen samples ( 1 of 98 samples) and $17 \%$ of the estradiol samples (34 of 102 samples).

\section{Immunohistochemistry}

I examined potential differences in AVT and NPY cell number among snakes using immunohistochemistry on two series of tissue, one for each neuropeptide. All slides were processed simultaneously within one immunohistochemistry assay per peptide. I used the methods described and validated by Lutterschmidt and Maine (2014). Briefly, slides were thawed at room temperature prior to incubating briefly ( $5 \mathrm{~min}$ ) in $4 \%$ paraformaldehyde in $0.1 \mathrm{M}$ phosphate-buffered saline (PBS; $\mathrm{pH}$ 7.4). Tissues were washed in $0.1 \mathrm{M}$ PBS three times for 5 min each; this was repeated after each step of the 
assay. The fixative was $\mathrm{n}+$ eutralized with $0.1 \%$ sodium borohydride $(\mathrm{pH} 8.5)$ and endogenous peroxidase activity was quenched with $3 \% \mathrm{H}_{2} \mathrm{O}_{2}$ in PBS. Slides were incubated with blocking serum containing $10 \%$ normal horse serum for AVT or $10 \%$ normal goat serum for NPY. AVT immunoreactivity was examined using a rabbit antiAVP antiserum (item 20069, ImmunoStar, Hudson, Wisconsin, USA) at a dilution of 1:5000. NPY immunoreactivity was examined using a rabbit anti-NPY antiserum (item 22940, ImmunoStar) at a dilution of 1:3000. Slides were incubated with primary antibody for $48 \mathrm{~h}$ in a humid chamber at $4{ }^{\circ} \mathrm{C}$. Primary antibody signal was amplified by incubation with biotinylated horse (for AVT) or biotinylated goat (for NPY) anti-rabbit IgG secondary antibody diluted 1:500 (products BA-1100 and BA-1000, respectively, Vector Labs Inc.). Slides were then incubated with avidin conjugated to horseradish peroxidase (Elite $\mathrm{ABC}$ peroxidase kit, Vector Labs, Inc.).

The NPY primary antibody signal was further amplified with biotin-labeled tyramide (item SAT700, Perkin Elmer, Piscataway, NJ) diluted 1:50 according to manufacturer instructions followed by a second incubation with avidin conjugated to horseradish peroxidase (Elite ABC peroxidase kit, Vector Laboratories, Inc.). AVT and NPY primary antibody binding was visualized using $0.25 \mathrm{mg} / \mathrm{ml}$ diaminobenzidine in $0.2 \%$ hydrogen peroxide in $0.05 \mathrm{M}$ Tris buffer ( $\mathrm{pH}$ 7.2). The reaction was terminated by immersion in nanopure $\mathrm{H}_{2} \mathrm{O}$. Tissues were dehydrated in a graded ethanol series, cleared with Citrisolv (Fisher Scientific, Pittsburg, Pa., USA) and covered with Permount and coverslips. 


\section{Immunoreactive Cell Counting}

Stained tissue was examined using an Olympus BX40 microscope with a QIClick digital camera and QImaging software (QImaging, Surrey, British Columbia, Canada). Locations of AVT- and NPY-immunoreactive (ir) cells were mapped onto standard anatomical brain sections adapted from Krohmer et al. (2010) and Martinez-Marcos et al. (2005, 2001). As in Lutterschmidt and Maine (2014), I observed three distinct populations of AVT-ir cells and four populations of NPY-ir cells in the brain of red-sided garter snakes. AVT-ir cell populations were located in the supraoptic nucleus (SON), anterior preoptic area (POA), and the bed nucleus of the stria terminalis (BNST). NPY-ir cell populations were located in the cortex (lateral, medial and dorsal regions), nucleus sphericus (NS), anterior hypothalamus (AH), and posterior hypothalamus (PH). It was difficult to establish consistent boundaries among AVT cell populations located in the POA and posterior hypothalamus, and therefore AVT-ir cells in these regions were combined into one population. Similarly, it was difficult to establish consistent boundaries among NPY cell populations located in the NS and the anterior and posterior dorsal ventricular ridge, and therefore NPY-ir cells in these regions were grouped together for analyses. As in Lutterschmidt and Maine (2014), the posterior hypothalamus population included NPY-ir cells located in the dorsomedial hypothalamic nucleus (DMN), lateral posterior hypothalamic nucleus (LHA), periventricular hypothalamic nucleus (PVN), and ventromedial hypothalamic nucleus (VMN).

Within each region of interest, -ir cells were counted manually; animals were coded so that the observer was blind to the identity of individuals. The number of AVT- 
and NPY-ir cells was quantified in each tissue section first under 200x magnification and again under 400x magnification. These counts were usually identical but in some cases differed by 1-3 cells. In these instances, the section was recounted under 400x magnification to verify the cell count. The number of AVT- and NPY- ir cells in each region was totaled for each individual. Because tissues were divided into four different series of $25-\mu \mathrm{m}$ sections, approximately $100-\mu \mathrm{m}$ separated each section within a series. In the regions of interest, AVT- and NPY-ir cells are approximately $10-12 \mu \mathrm{m}$ in diameter. Thus, there is no possibility that double counting of cells split between two sections inflated my cell numbers. In addition, a labeled cell was counted only if it was of the same general size and shape as the other -ir cells in the region of interest, thereby excluding partial cells from my quantifications.

I followed the counting methods and criteria described by Laberge et al. (2008) and used in Maine et al. (2014) to account for missing and/or damaged sections. Within each region of interest, the number of AVT- and NPY-ir cells for an individual was calculated as the total number of labeled cells divided by the total number of usable brain sections multiplied by the average number of brain sections for a given region across all animals. I calculated the total number of labeled cells in males and females separately because body size (and therefore brain size) is sexually dimorphic. These counting methods allowed me to retain more animals in the statistical analyses [instead of eliminating an animal if two or more consecutive sections were missing or damaged (e.g., Lutterschmidt and Wilczynski, 2012)]. The mean number of missing or damaged sections across all animals and regions was $0.65( \pm 0.06 \mathrm{SE})$ and $1.86( \pm 0.09 \mathrm{SE})$ for AVT and NPY, respectively. Any animal missing greater than $30 \%$ of its sections within a region 
of interest was excluded from statistical analyses. Final sample sizes for each region of interest are shown in the figures.

Finally, two of the four NPY-ir cell populations are localized within two very large bilateral brain regions: the cortex and NS. To determine if cell counts from one hemisphere could be used for analysis, I compared the total number of NPY-ir cells between the left and right hemispheres for both the cortex and NS. To do this, I used a subset of males and females collected during this study ( $\mathrm{n}=9$ males and 9 females). As reported in the results, there was no difference in NPY-ir cell number between the left and right hemispheres within either the cortex or NS. I therefore used NPY-ir cell counts from one hemisphere for all subsequent analyses within the cortex and NS. With the exception of the relatively small population of AVT-ir cells within the BNST, all other regions of interest containing AVT and NPY cells were not bilateral.

Normalization of sexual size dimorphism for direct sex comparisons

I wanted to directly compare numbers of AVT and NPY cells between sexes. However, male and female red-sided garter snakes are sexually size dimorphic, and this produces a concomitant sex dimorphism in both overall brain size and likely regional brain volumes. Thus, I needed to correct the number of -ir cells for differences in brain size before directly comparing males and females. Note that differences in brain size can reflect differences in either cell number or cell volume. For these comparisons, I asked if SVL could be used to accurately represent differences in regional brain volume. To address this question, I counterstained a series of tissue from this experiment using $0.25 \%$ 
toluidine blue in $70 \%$ ethanol. I then quickly rinsed the tissues in nanopure $\mathrm{H}_{2} \mathrm{O}$ (2 dips) followed by $95 \%$ ethanol (4 dips) and then covered the tissues with Permount and coverslips. I used a subset of 18 females and 20 males for this analysis, with differences in season and migratory status equally represented within each sex.

I chose two brain regions for this analysis that are both seasonally variable and sexually dimorphic: the medial cortex and NS (Holding et al., 2012; Kabelik et al., 2006; Krohmer et al., 2011; Crews et al., 1993). Because only NPY cells, and not AVT cells, occur in the medial cortex and NS, I distinguished the boundaries of these regions using the same brain atlas used for counting NPY cells (Lutterschmidt and Maine, 2014; Krohmer et al., 2010; Martínez-Marcos et al., 2001), and then outlined the region of interest and measured its area using the calibrated measure feature of Image J software $(\mathrm{NIH})$; I repeated this procedure for every tissue section containing the region of interest. I calculated the total regional volume $\left(\mu \mathrm{m}^{3}\right)$ for each animal by first summing the areas measured on each tissue section, multiplying by four to account for all tissue series, and then multiplying by $25-\mu \mathrm{m}$ to account for section thickness.

Statistical Analyses

Data were transformed where necessary using log, square root, or natural log to meet the assumptions necessary for parametric analysis. When data transformation could not correct for non-normality and/or unequal variance, I used a nonparametric MannWhitney $U$-test or a Scheirer-Ray-Hare extension of the Kruskal-Wallis analysis. I used SigmaPlot 12.0 (Systat Software 2010, Systat Systems, Inc., Point Richmond, CA) for all 
statistical analyses. Statistical comparisons were considered significant at $\mathrm{p} \leq 0.05$.

For the large bilateral NPY-ir cell populations located in the cortex and NS, I verified that I could use cell counts from one brain hemisphere for analysis by comparing the number of NPY-ir cells between the left and right hemispheres using paired t-tests. I determined if SVL could be used as a proxy for regional brain volume by examining the relationship between the volume of the medial cortex or NS and SVL using linear regressions. I also compared the results obtained from a two-way ANOVA with season and migratory status as factors on NPY-ir cell number corrected by brain region volume (after multiplying cell counts by four to account for all tissue series) to those obtained from a two-way ANOVA using NPY-ir cell number corrected by SVL.

In Experiment 1, I used a two-way ANOVA within each sex to confirm that body size did not vary with season or migratory status. I then asked if AVT- or NPY-ir cell number changed seasonally or with migratory status in male and female snakes. To address this question, I first corrected my cell counts for sex differences in brain volume by dividing the total number of - ir cells for each individual by its SVL. I then compared these SVL-corrected data using a three-way ANOVA with season, sex, and migratory status as between-subjects factors for each neuropeptide and brain region of interest. These initial analyses allowed us to directly examine possible sex differences in -ir cell number within each region of interest. Because the main effects of sex were statistically non-significant in all but one region, I separated the AVT- and NPY-ir cell counts by sex and reanalyzed the data using a two-way ANOVA with season and migratory status as between-subjects factors for each neuropeptide and region of interest. This allowed me to better evaluate the relationship between neuropeptides, season, and migration, by 
decreasing the number of pairwise comparisons. Rather than collapsing sex as a factor and combining males and females for analysis, I opted to analyze potential differences in neuropeptides within each sex separately due to a priori knowledge that males and females exhibit differences in the onset and timing of seasonal migration (Shine et al., 2001). For these analyses, I used cell count data that were not corrected by SVL (because SVL did not vary significantly with season or migratory status within each sex).

Lastly, I used the data from Experiment 1 to determine if variation in -ir cell number within the brain was related to seasonal changes in plasma sex steroid hormone or corticosterone concentrations. I limited my comparisons to those brain regions with significant seasonal variation in -ir cell number. As described in the results, these regions included AVT within the SON, POA, and BNST of males, AVT within the POA of females, and NPY within the cortex and PH of males. I used hormone concentrations measured immediately before brain collection for all analyses so that I could more directly assess the relationship between neuropeptide cell number and plasma steroid hormone concentrations.

In Experiment 2, I used t-tests to confirm that body size of snakes did not differ between reproductive states. I then used a t-test within each region of interest to compare -ir cell number between snakes with differing reproductive conditions. For each neuropeptide, I compared mated and unmated females collected from the den and courting and non-courting males collected from the road. Each of these comparisons allowed me to assess potential changes in AVT and/or NPY in relation to changes in reproductive behavior while holding migratory status constant. 


\section{Results}

There were no significant differences in the total number of NPY-labeled cells between the left and right hemispheres within the cortex $(\mathrm{t}=0.61, \mathrm{df}=17, \mathrm{p}=0.55)$ or $\mathrm{NS}(\mathrm{t}=0.99, \mathrm{df}=17, \mathrm{p}=0.34$; from paired $\mathrm{t}$-tests $)$. I therefore used cell counts from one hemisphere for all subsequent analyses of NPY-ir cell number within the cortex and NS.

To determine if SVL could be used to correct -ir cell number for variation in regional brain volume, I examined if region volume changed linearly with SVL. There was a significant positive linear relationship between medial cortex volume and SVL $\left(\mathrm{r}^{2}\right.$ $=0.30, \mathrm{p}<0.001, \mathrm{n}=18$ females and 18 males $)$. There was also a significant positive linear relationship between NS volume and SVL $\left(r^{2}=0.42, p<0.001, n=18\right.$ females and 20 males). Lastly, there were no differences between the results obtained from a two-way ANOVA (with season and migratory status as factors) using NPY-ir cell number/region volume and those results obtained using NPY-ir cell number/SVL (data not shown). Thus, I used SVL to correct for sex differences in regional brain volumes for all subsequent analyses directly comparing males to females.

Experiment 1. Seasonal and Sexual Variation in Brain AVT and NPY: Relation to Migratory Behavior

Body size (i.e., SVL) of male snakes did not vary significantly with season ( $\mathrm{F}_{1,39}$ $<0.01, \mathrm{p}=0.97)$ or migratory status $\left(\mathrm{F}_{1,39}=2.61, \mathrm{p}=0.11\right.$; two-way ANOVA $)$. There were no significant differences in the SVL of female snakes between seasons $\left(F_{1,40}=\right.$ 
$1.60, \mathrm{p}=0.21)$ or migratory states $\left(\mathrm{F}_{1,40}=3.73, \mathrm{p}=0.06\right.$; two-way ANOVA $)$. There were no significant interactions between season and migratory status on the SVL of male $\left(\mathrm{F}_{1,39}\right.$ $<0.01, \mathrm{p}=0.98)$ or female $\left(\mathrm{F}_{1,40}=0.41, \mathrm{p}=0.53\right)$ snakes.

AVT Immunoreactivity

For each region of interest described below, I first compared AVT-ir cell number directly between males and females using a three-way ANOVA on SVL-corrected data. For all regions except the POA, I did not observe a significant sex difference in AVT-ir cell number nor any significant interactions between sex and the other factors (all pvalues $>0.10$ ). To reduce manuscript length, I report the results of the three-way ANOVA only for the POA. I then separated the data by sex and reanalyzed the uncorrected data (i.e., not divided by SVL) within each region of interest using a twoway ANOVA to focus on potential variation due to season and migratory status.

Supraoptic Nucleus. A two-way ANOVA indicated that male snakes had significantly more AVT-ir cells during the fall compared to spring in the SON (Fig. 1A; $\mathrm{F}_{1,34}=5.98, \mathrm{p}=0.02$ ), whereas female snakes did not show a significant seasonal difference (Fig. 1B; $\mathrm{F}_{1,31}=1.64, \mathrm{p}=0.21$ ). Migratory status did not influence the total number of AVT-ir cells in the SON of male (Fig. $1 \mathrm{~A} ; \mathrm{F}_{1,34}=2.93, \mathrm{p}=0.10$ ) or female snakes (Fig. 1B; $F_{1,31}=0.09, p=0.77$ ). There was no interaction between season and migratory status in male snakes $\left(\mathrm{F}_{1,34}=0.15, \mathrm{p}=0.70\right)$. In females, the interaction between season and migratory status in the total number of AVT-ir cells in the SON was 
significant $\left(\mathrm{F}_{1,31}=5.33, \mathrm{p}=0.03\right)$.

Anterior Preoptic Area. A three-way ANOVA with season, sex, and migratory status as factors indicated that female snakes had significantly more AVT-ir cells in the POA compared to males, even after correcting for differences in body size $\left(\mathrm{F}_{1,69}=13.12\right.$, $\mathrm{p}<0.001$; data not shown). Females had an overall mean of 6.9 AVT-ir cells per cm SVL ( $\pm 0.34 \mathrm{SE})$; males had an overall mean of 5.5 AVT-ir cells per cm SVL $( \pm 0.28 \mathrm{SE})$. The total number of AVT-ir cells/SVL in the POA was also significantly higher during the spring compared to fall $\left(\mathrm{F}_{1,69}=9.69, \mathrm{p}<0.01\right)$. Migratory status did not significantly influence the total number of AVT-ir cells/SVL in the POA $\left(\mathrm{F}_{1,69}<0.01, \mathrm{p}=0.98\right)$. There were no significant interactions in any combination of season, sex, and migratory status on SVL-corrected AVT-ir cell number in the POA (all p-values $\geq 0.10$ ).

After separating these data by sex, two-way ANOVAs on the uncorrected data indicated that both male (Fig. 1C; $\mathrm{F}_{1,34}=8.16, \mathrm{p}<0.01$ ) and female (Fig. 1D; $\mathrm{F}_{1,34}=5.35$, $\mathrm{p}=0.03$ ) snakes had significantly more AVT-ir cells in the POA during the spring compared to the fall. Migratory status did not significantly influence the total number of AVT-ir cells in the POA of males (Fig. $1 \mathrm{C} ; \mathrm{F}_{1,34}=2.37, \mathrm{p}=0.13$ ) or females (Fig. 2D; $\left.\mathrm{F}_{1,34}<0.01, \mathrm{p}=0.99\right)$. There were no significant interactions between season and migratory status on the total number of AVT-ir cells of male $\left(\mathrm{F}_{1,34}=0.08, \mathrm{p}=0.78\right)$ or female $\left(\mathrm{F}_{1,34}=0.22, \mathrm{p}=0.64\right)$ snakes in the POA.

Bed Nucleus of the Stria Terminalis. A two-way ANOVA indicated that male snakes had significantly more AVT-ir cells in the BNST during the spring compared to 
fall (Fig. $1 \mathrm{E} ; \mathrm{F}_{1,32}=6.98, \mathrm{p}=0.01$ ). Female snakes did not show a significant seasonal difference in AVT-ir cell number in the BNST (Fig. 1F; $\mathrm{F}_{1,28}=3.71, \mathrm{p}=0.07$; two-way ANOVA). Migratory status did not significantly influence the total number of AVT-ir cells in the BNST of male (Fig. 1E; $F_{1,32}=0.17, p=0.68$ ) or female snakes (Fig. 1F; $F_{1,28}$ $=2.09, \mathrm{p}=0.16$ ), although the low sample size of road-collected females during the fall suggests that any conclusions should be made with caution. There was a significant interaction between season and migratory status on the total number of AVT-ir cells in the BNST of male snakes $\left(\mathrm{F}_{1,32}=4.15, \mathrm{p}=0.05\right)$. There was no such interaction between season and migratory status in female snakes within the BNST $\left(\mathrm{F}_{1,28}=2.10, \mathrm{p}=0.16\right)$.

\section{NPY Immunoreactivity}

For each region of interest described below, I first compared NPY-ir cell number directly between males and females using a three-way ANOVA on SVL-corrected data. For all NPY regions, there were no significant sex difference in NPY-ir cell number nor any significant interactions between sex and any combination of the other factors (all pvalues $>0.10$ ). I therefore separated the data by sex and reanalyzed NPY-ir cell number within each region of interest using a two-way ANOVA to focus on potential variation related to season and migratory status.

Cortex. A two-way ANOVA indicated that male snakes had significantly more NPY-ir cells in the cortex during the fall compared to spring (Fig. $2 \mathrm{~A} ; \mathrm{F}_{1,35}=12.74, \mathrm{p}<$ 0.001), whereas female snakes did not show a significant seasonal difference (Fig. 2B; 
$\mathrm{F}_{1,31}=2.01, \mathrm{p}=0.17$; two-way ANOVA). Migratory status did not significantly influence the total number of NPY-ir cells in the cortex of male (Fig. $2 \mathrm{~A} ; \mathrm{F}_{1,35}=0.50, \mathrm{p}=0.48$ ) or female snakes (Fig. $2 \mathrm{~B} ; \mathrm{F}_{1,31}=0.95, \mathrm{p}=0.34$ ). There were no significant interactions between season and migratory status in the cortex of male $\left(\mathrm{F}_{1,35}=1.11, \mathrm{p}=0.30\right)$ or female $\left(\mathrm{F}_{1,31}=0.91, \mathrm{p}=0.35\right)$ snakes.

Nucleus Sphericus. In male snakes, neither season $\left(\mathrm{F}_{1,32}=2.39, \mathrm{p}=0.13\right)$ nor migratory status $\left(\mathrm{F}_{1,32}=0.02, \mathrm{p}=0.89\right)$ influenced NPY-ir cell number in the NS (Fig. 2C; two-way ANOVA). Similarly, female snakes showed no main effects of season $\left(\mathrm{H}_{1,25}\right.$ $=0.46, \mathrm{p}=0.49)$ or migratory status $\left(\mathrm{H}_{1,25}=0.03, \mathrm{p}=0.86\right)$ on NPY-ir cell number in the NS (Fig. 2D; nonparametric two-way ANOVA). There were no significant interactions between season and migratory status on the total number of NPY-ir cells in the NS of male $\left(\mathrm{F}_{1,32}=0.39, \mathrm{p}=0.54\right)$ or female snakes $\left(\mathrm{H}_{1,25}=0.06, \mathrm{p}=0.80\right)$.

Anterior Hypothalamus. A two-way ANOVA indicated that male snakes showed no significant effects of season $\left(\mathrm{F}_{1,30}<0.01, \mathrm{p}=0.99\right)$ or migratory status $\left(\mathrm{F}_{1,30}=0.15, \mathrm{p}\right.$ $=0.70)$ on NPY-ir cell number in the AH (Fig. 2E). Similarly, female snakes showed no significant main effects of season $\left(\mathrm{F}_{1,31}=0.94, \mathrm{p}=0.34\right)$ or migratory status $\left(\mathrm{F}_{1,31}=2.59\right.$, $\mathrm{p}=0.12)$ on NPY-ir cell number in the AH (Fig. 2F; two-way ANOVA). There were no significant interactions between season and migratory status in the total number of NPYir cells in the AH of male $\left(F_{1,30}=0.23, p=0.63\right)$ or female snakes $\left(F_{1,31}=0.30, p=0.59\right)$.

Posterior Hypothalamus. A nonparametric two-way ANOVA indicated that male 
snakes had significantly more NPY-ir cells in the PH during the fall compared to the spring (Fig. $2 \mathrm{G} ; \mathrm{H}_{1,31}=6.78, \mathrm{p}<0.01$; nonparametric two-way ANOVA), whereas female snakes showed no significant seasonal difference (Fig. $2 \mathrm{H} ; \mathrm{F}_{1,29}=0.28, \mathrm{p}=0.60$; two-way ANOVA). Migratory status did not significantly influence the total number of NPY-ir cells in the PH of male (Fig. 2G; $\mathrm{H}_{1,31}<0.01, \mathrm{p}=0.97$ ) or female snakes (Fig. $\left.2 \mathrm{H} ; \mathrm{F}_{1,29}=0.73, \mathrm{p}=0.40\right)$. There was no significant interaction between season and migratory status in the number of NPY-ir cells in the PH of male snakes $\left(\mathrm{H}_{1,31}=0.99, \mathrm{p}=\right.$ 0.32), but females showed a significant interaction between season and migratory status on NPY-ir cell number in the PH $\left(\mathrm{F}_{1,29}=5.17, \mathrm{p}=0.03\right)$.

\section{Relationship between neuropeptides and steroid hormone.}

Based on the observed seasonal differences in AVT- and NPY-ir cell number, I asked if variation in neuropeptide cell number within the brain was related to plasma steroid hormone concentrations. I limited my comparisons to those regions showing a significant seasonal difference in -ir cell number; males and females were analyzed separately. Thus, I used linear regressions to examine the relationship between neuropeptide cell number (i.e., AVT in the SON, POA and BNST and NPY in the cortex and $\mathrm{PH}$ ) and steroid hormones (i.e., androgens and corticosterone) in male snakes. In females, I examined the relationship between AVT-ir cell number in the POA and estradiol or corticosterone.

There were no significant relationships between androgen concentrations and AVT-ir cell number within the SON $\left(r^{2}=0.06, p=0.17\right)$, POA $\left(r^{2}=0.06, p=0.18\right)$, or 
BNST $\left(r^{2}<0.01, p=0.75\right)$ of male snakes. There were also no significant relationships between corticosterone and AVT-ir cell number within the $\operatorname{SON}\left(r^{2}<0.01, p=0.63\right)$, POA $\left(\mathrm{r}^{2}<0.01, \mathrm{p}=0.63\right)$, or BNST $\left(\mathrm{r}^{2}<0.01, \mathrm{p}=0.83\right)$ of males. In female snakes, AVT-ir cell number in the POA was positively related to estradiol concentration (Fig. $\left.3 \mathrm{~A} ; \mathrm{r}^{2}=0.11, \mathrm{p}=0.05\right)$ and negatively related to corticosterone concentrations (Fig. 3B; $\left.r^{2}=0.14, p=0.03\right)$. When all samples that were assigned the assay sensitivity were removed from this analysis, the relationship between AVT-ir cell number in the POA and estradiol was not significantly related $\left(\mathrm{r}^{2}=0.10, \mathrm{p}=0.17\right)$. Finally, neither androgens nor corticosterone were significantly related to NPY-ir cell number in the cortex $\left(\mathrm{r}^{2}<0.01, \mathrm{p}\right.$ $=0.76 ; \mathrm{r}^{2}<0.01, \mathrm{p}=0.76$, respectively) or $\mathrm{PH}\left(\mathrm{r}^{2}<0.01, \mathrm{p}=0.64 ; \mathrm{r}^{2}<0.01, \mathrm{p}=1.00\right.$, respectively) of male snakes.

Experiment 2. Changes in Brain AVT and NPY during the Spring Mating Season: Relation to Reproductive Status

I asked if changes in AVT- or NPY-ir cell number in the brain were related to the transition from courting to non-courting in male snakes, or from unmated to mated status in female snakes. Body size (i.e., SVL) did not differ significantly between courting and non-courting males $(\mathrm{t}=0.06, \mathrm{df}=20, \mathrm{p}=0.95)$ or unmated and mated females $(\mathrm{t}=1.42$, $\mathrm{df}=19, \mathrm{p}=0.17$; results from t-tests). Within the SON, non-courting males had significantly more AVT-ir cells compared to courting males (Fig. 4A; $\mathrm{t}=-2.68, \mathrm{df}=18$, $\mathrm{p}=0.02$; $\mathrm{t}$-test). There was no significant difference in AVT-ir cell number between unmated and mated females within the SON (Fig. 4B; $t=1.31$, $d f=15, p=0.21$; $t$-test). 
Within the POA, there were no statistically significant differences in AVT-ir cell number between courting and non-courting males (Fig. $4 \mathrm{C} ; \mathrm{t}=-2.02, \mathrm{df}=19, \mathrm{p}=0.06$ ) or between unmated and mated females (Fig. 4D; $t=0.91, d f=18, p=0.37$ ). Within the BNST, there were no significant differences in AVT-ir cell number between courting and non-courting males (Fig. $4 \mathrm{E} ; \mathrm{t}=0.33, \mathrm{df}=18, \mathrm{p}=0.74$ ) or unmated and mated females (Fig. $4 \mathrm{~F} ; \mathrm{t}=1.01, \mathrm{df}=15, \mathrm{p}=0.33$ ).

Within the cortex, non-courting males had significantly more NPY-ir cells compared to courting males (Fig. $5 \mathrm{~A} ; \mathrm{t}=-2.07, \mathrm{df}=20, \mathrm{p}=0.05$ ). There was no difference in NPY-ir cell number between unmated and mated females within the cortex (Fig. $5 \mathrm{~B} ; \mathrm{t}=-0.25, \mathrm{df}=17, \mathrm{p}=0.80$ ). Within the NS, there was no significant difference in NPY-ir cell number between courting and non-courting males (Fig. $5 \mathrm{C} ; \mathrm{t}=-1.69, \mathrm{df}=$ $16, p=0.11)$ or between unmated and mated females (Fig. $5 \mathrm{D} ; \mathrm{t}=-0.50, \mathrm{df}=14, \mathrm{p}=$ 0.63). Within the AH, there was no significant difference in NPY-ir cell number between courting and non-courting males (Fig. $5 E ; t=-1.57, d f=16, p=0.14$ ) or between unmated and mated females (Fig. 5F; $\mathrm{t}=1.02, \mathrm{df}=17, \mathrm{p}=0.32$ ). Within the $\mathrm{PH}$, there was no difference in NPY-ir cell number between courting and non-courting males (Fig. $5 \mathrm{G} ; \mathrm{t}=0.81, \mathrm{df}=18, \mathrm{p}=0.43$ ) or between unmated and mated females (Fig. $5 \mathrm{H} ; \mathrm{t}=1.15$, $\mathrm{df}=16, \mathrm{p}=0.27)$

\section{Discussion}

My findings suggest that the number of AVT- and NPY-ir cells within brain regions important for regulating reproduction, migration, and feeding varies with season, 
sex, and life-history stage. For example, males had more AVT-ir cells in two brain regions important for reproductive behavior during the spring mating season (POA, BNST). During the fall, male snakes had more AVT-ir cells in the SON, a brain region which transports AVT from the hypothalamus to the pituitary for systemic release. Males also had more NPY-ir cells during the fall after the summer feeding season in two brain regions: one which is important for spatial memory (cortex) and one which regulates feeding behavior $(\mathrm{PH})$. Similar to males, females also had significantly more AVT-ir cells in the POA during the spring compared to fall. However, a higher number of AVTir cells were observed within the POA of females compared to males, potentially reflecting an earlier activation of reproductive physiology in females. In male snakes, the number of -ir cells varied with reproductive status, but not directly with migratory status in both the cortex and SON. By contrast, I observed little variation in -ir cell number with migratory or reproductive status in female snakes. These data suggest a role for AVT and NPY in mediating the seasonal life-history transitions from reproductive to migration via regulation of reproductive behavior, and not migration per se. My findings help to highlight the role that AVT and NPY play in the reconfiguration of regulatory systems during life-history transitions in red-sided garter snakes.

\section{Seasonal Differences}

From late April through mid-May, northern populations of red-sided garter snakes emerge from underground winter hibernacula and engage in an intense mating period at the den, after which they migrate to summer feeding grounds (Shine et al., 2001). I 
compared snakes collected during the spring mating season and the fall to examine if variation in ir-cell number was related to seasonal changes in behavior in red-sided garter snakes, with the expectation that there would be more AVT-ir cells during the spring mating season in brain regions that are important for reproductive behavior. Indeed, male and female snakes had more AVT-ir cells during the spring in the POA, and males had more AVT-ir cells within the BNST during the spring. Both regions are known to play important roles in reproductive behavior in many vertebrates (Ball and Balthazart, 2011; Xie et al., 2010; Kabelik et al., 2008; Lanuza and Halpern, 1997; Krohmer and Crews, 1987a, b). Toyoda et al. (2003) observed increased courtship behavior and release of female-attracting pheromone following treatment with exogenous AVT in male redbellied newts (Cynops pyrrhogaster). Additionally, Kabelik et al. (2013) used cFos labeling to observe activation of AVT neurons within the POA and BNST in adult male brown anole lizards (Anolis sagrei) engaging in courtship behavior. The seasonal difference I observed in AVT-ir cell number in the POA and BNST suggests that AVT may be mediating seasonal changes in reproductive behavior in red-sided garter snakes.

Following the summer feeding season, male and female snakes return to the den in preparation for winter dormancy. During this fall pre-hibernation period, I observed significantly more AVT-ir cells within the SON of male snakes and a significant season by migratory status interaction in female snakes. Numerous studies in mammals have demonstrated that SON neurons transport AVP from the hypothalamus to the posterior pituitary for systemic release (reviewed in Landgraf and Neumann, 2004). A conserved function of the SON is supported in another snake species, Jararaca vipers (Bothrops jararaca) (Zambotti-Villela et al., 2007). As a neurohormone, AVT/P primarily regulates 
water balance (Ludwig et al., 1996), but it has also been shown to directly stimulate release of adrenocorticotropic hormone and increase glucocorticoid synthesis (e.g., Madison et al., 2008). The higher AVT-ir cell number I observed during the fall in redsided garter snakes is likely related to the greater demands of maintaining water balance during extended terrestrial activity, but it might also explain higher plasma glucocorticoid concentrations of male and female snakes during the fall (Lutterschmidt and Mason, 2005). For example, Dunham and Wilczynski (2014) observed an increase in plasma glucocorticoid concentrations in response to exogenous AVT in male green anole lizards (A. carolinensis). Overall, additional studies are needed to understand the role of AVT in regulating seasonal rhythms in physiology (e.g., water balance) and behavior (e.g., reproduction) in this and other reptile species, as this information is critical to understanding the function and evolution of the AVT/AVP neuropeptide system.

Following the summer foraging period, I observed more NPY-ir cells within the $\mathrm{PH}$ of males during the fall and a significant interaction between season and migratory status in female snakes. The PH is composed of NPY-sensitive nuclei that are activated by NPY-ir cells and include the LHA, PVN and VMN. When treated with exogenous NPY into these nuclei, increased food intake is observed in rodents (reviewed by Chee and Colmers, 2008). Indeed, male red-sided garter snakes, increase feeding behavior after exogenous NPY treatment (Morris and Crews, 1990), supporting my original hypothesis that NPY-ir cells in the PH are likely related to foraging behavior.

During the fall pre-hibernation period, I also observed more NPY-ir cells within the cortex of male snakes. The cortex is composed of lateral, dorsal and medial regions; the dorsal and medial cortex is a structural and functional homologue of the hippocampus 
of birds and mammals (Butler and Hodos, 1996) and is important for spatial memory in snakes (Holding et al., 2012; Roth et al., 2006). Indeed, Roth et al. (2006) observed larger medial cortex volume in male cottonmouth snakes (Agkistrodon piscivorus), which reside and navigate through larger areas compared to females. The hippocampus (and its vertebrate homologues) is well known for its seasonal plasticity (e.g., Migaud et al., 2011). For example, Barnea and Nottebohm (1994) observed greater neuronal recruitment in the hippocampus of black-capped chickadees (Poecile atricapillus) during peak spatial use in the fall. Together, these results suggest that the greater NPY-ir cell number in male snakes may be related to the spatial memory required for migration back to the den site during the fall, but future research needs to examine this hypothesis to understand why females did not exhibit a seasonal difference similar to males. While I do not have a clear understanding of how NPY in the cortex may relate to spatial memory, perhaps NPY is playing a neuromodulatory role outside of the hypothalamus (Schneider et al., 2013; Wójcik-Gładysz and Polkowska, 2006; McShane et al., 1992; Danger et al., 1990). NPY in the cortex could be related to decreased stress sensitivity that is observed in male red-sided garter snakes during the spring (C. Dayger, personal communication). Future studies are needed to examine the relationship between NPY in the cortex and the hypothalamus-pituitary-adrenal axis modulation of stress responsiveness in male and female snakes.

Sex Differences

Numerous studies have demonstrated a higher number of AVT-ir cells in males 
compared to females in multiple AVT brain regions (reviewed in Goodson and Bass, 2001). By contrast, I found significantly more AVT-ir cells within the POA of female red-sided garter snakes than males, even after correcting for differences in body size. While generally uncommon, these results are not without precedence. For example, Maruska et al. (2007) reported that female halfspotted gobies (Asterropteryx semipunctata) had larger and more AVT-ir cells in the POA compared to males during peak-spawning (i.e., egg development and ovulation) and non-spawning stages. In redsided garter snakes, the POA is important for reproduction and contains sex steroid concentrating neurons (Halpern et al., 1982; Krohmer and Crews, 1987a, b). For instance, Krohmer and Crews (1987b) observed no courtship behavior in male red-sided garter snakes with bilateral lesions to the AH-POA during the mating season. Thus, AVT-ir cells in the POA may regulate reproductive physiology and behavior in red-sided garter snakes. Additionally, I observed a positive relationship between AVT-ir cell number in the POA and estradiol concentration and a negative relationship between AVT-ir cells in the POA and corticosterone concentration in females. Taken together, AVT in the POA could be related to earlier dispersal in females, compared to males, and earlier activation of summer gametogenesis; additional studies examining how AVT changes during the summer in both sexes are needed to test this hypothesis.

While males exhibited seasonal differences in AVT and NPY in almost all regions of interest, seasonal differences in AVT- and NPY-ir cell number were generally lacking in female snakes. However, in two regions of interest (AVT in the SON and NPY in the $\mathrm{PH})$, the seasonal difference depended upon migratory status in females, as evidenced by significant interactions between factors. These significant interactions in females support 
a more traditional role for AVT in the SON and NPY in the PH of females, of systemic AVT transport and feeding behavior regulation, respectively. Comparatively, I observed a significant seasonal difference in AVT-ir cells within the BNST in males. Perhaps the BNST is more important for male specific courtship behavior when compared to female reproductive behavior. For example, male snakes remain near the den for several weeks to court newly emerging females, whereas female snakes typically emerge from the den, mate within $24 \mathrm{~h}$, and then disperse from the den to summer feeding grounds (Shine et al., 2001). However additional studies are needed to examine the function of AVT within the BNST.

\section{Differences Related to Migratory and Reproductive Status}

Overall, migratory status did not have a significant main effect on neuropeptide cell number. However, I did observe a significant interaction between season and migratory status in three regions of interest (AVT-ir cells in the BNST of males, AVT-ir cells in the SON of females, and NPY-ir cells in the PH of females), suggesting further research is needed to understand if and how AVT and NPY are related to seasonal changes in migratory behavior. Future studies using more sensitive techniques (e.g., qPCR or in situ hybridization to examine changes in gene expression) would also aid in understanding the nature and importance of sexually dimorphic seasonal changes in AVT and NPY. The red-sided garter snake system would be advantageous for such studies, as it will allow changes related to migration to be assessed independently from those related to reproductive status. 
By contrast, I observed significant variation in immunoreactivity related to changes in reproductive status. Non-courting male snakes had more AVT-ir cells in the SON compared to courting male snakes. As discussed previously, increased AVT-ir cell number in the SON is likely related to maintaining water balance; my results suggest that the seasonal change in AVT within the SON (Fig. 1A) is concomitant with the seasonal transition to non-reproductive status in male snakes (Fig. 5A). Similar to my findings, Canada geese (Branta canadensis) have more intense AVT staining in the anterior median eminence and neurohypophysis prior to spring migration compared to postmigration (George and John, 1987). The authors suggest that AVT initiates spring migration in many migratory birds as well as aids in maintaining water balance during challenging life-history stages. However, my results in red-sided garter snakes suggest that seasonal changes in AVT in the SON may be more closely related to seasonal transitions in reproductive life-history stages than migration per se. Because of my study design, I were able to examine changes in AVT-ir cell number related to reproductive stage and migration independently. Interestingly, AVT-ir cell number in the POA and BNST did not differ significantly between courting and non-courting male snakes. Although I do not yet know if AVT regulates courtship behavior in any snake species, my results corroborate those of Lutterschmidt and Maine (2014), who suggested that a lack of change in brain AVT during the seasonal transition from reproduction to feeding behavior may enable males to maximize reproductive opportunities.

I also observed more NPY-ir cells in non-courting compared to courting males in the cortex which mirror the higher number of NPY-ir cells observed in the cortex during the fall. Again, this could be related to spatial memory. Alternatively, these results are 
also similar to those observed by Lutterschmidt and Maine (2014), in which a higher NPY-ir cell number occurred in the cortex of feeding snakes. Together, this suggests that the seasonal difference in NPY is concomitant with transitions from reproductive to feeding behavior, but the role of NPY in the cortex is unknown. Alternatively, it is well established that NPY in the hypothalamus suppresses sex behavior in many animals (Schneider, 2004; Schneider et al., 2013), including red-sided garter snakes (Morris and Crews, 1990). Perhaps NPY in the cortex acts as a neuromodulator and is also related to a down-regulation of courtship behavior. Specifically, as male snakes migrate to summer feeding grounds from the den during the spring, reproductive behavior wanes and snakes transition to foraging behavior (Cease et al., 2007; O’Donnell et al., 2004; Gregory and Stewart, 1975).

\section{Conclusions}

I examined seasonal and sex differences in AVT and NPY in relation to migratory and reproductive status. During the spring mating season, I observed a higher number of AVT-ir cells within two brain regions important for reproductive behavior, supporting a role for AVT as a mediator of reproductive behavior in red-sided garter snakes. Future studies are needed to examine the effects of exogenous AVT treatment on courtship behavior. During the fall, NPY appears to be related to feeding and foraging behavior via the PH and may also play a role in migration and spatial memory via the cortex of male snakes. Alternatively, NPY in the cortex of males could be related to suppressed sensitivity to stress. Additional studies are needed to examine how changes in brain NPY 
relate to seasonal changes in feeding behavior both prior to and during migration to the feeding grounds. Collectively, my results suggest that AVT and NPY may play a more prominent role in modulating seasonal transitions in reproductive behavior rather than migration per se, although additional studies are needed to understand the observed region-specific interactions between season and migratory status. It is also unknown why females exhibit fewer seasonal differences than male snakes and additional time points during the summer. My data provide a better understanding of the role AVT and NPY play in the neuroecology of life-history transitions, and more importantly, have given insight into the role of neuropeptides during seasonal life-history transitions under natural field conditions. 


\section{CHAPTER 3: Conclusions and Future Directions}

Prior to this work, no study had investigated changes in both AVT and NPY cell number during a natural life-history transition. My work is novel because past studies

only examined a single behavior within a season, for example pre-migration or postmigration stages but not throughout a migratory event. My findings are important to help us understand how behaviors become activated or deactivated and how transitions in behaviors are modulated across seasons. This work is also important as it helps to better understand how internal context (e.g., season, sex, migratory and reproductive status) plays a role in regulating behavior, which will help us predict how animals will respond to changing environments. For example, having an understanding of how an animal activates and deactivates behaviors in an ecologically relevant context, provides a base for future research examining how behaviors are activated/deactivated with a temperature change. Previous research has demonstrated the importance of glucocorticoid hormones in life-history transitions during migration, and my results add the peptides AVT and NPY to the roster of critical players in life-history transitions. Additional studies are now needed to understand how glucocorticoids and neuropeptides interact to modify behavior, and whether hormones or neuropeptides are at the forefront of inducing behavioral transitions. Some of the future work that needs to be conducted to answer these questions is described within this chapter. 


\section{Seasonal Differences}

I observed significantly more AVT-ir cells during the spring compared to the fall within the POA and BNST of males and POA of females. I observed a similar trend within the BNST of females $(\mathrm{p}=0.07)$ which could be biologically relevant, although not statistically significant. As previously discussed, the POA and BNST are important for reproductive behavior (Ball and Balthazart, 2011; Xie et al., 2010; Kabelik et al., 2008; Lanuza and Halpern, 1997), but it will be important to understand the function of the POA and BNST within each sex. I may not have observed differences in AVT-ir cell number in the BNST of females because the BNST could be important for male specific courtship behavior. Although, a larger sample size examining AVT-ir cells within the BNST of female snakes could show a similar seasonal difference as male snakes. Future studies will need to examine male and female specific behavior following manipulation of the BNST via exogenous AVT treatment or ablation of the BNST region.

I observed significantly more NPY-ir cells during the fall compared to spring within the cortex of males. As previously discussed, the cortex is important for spatial navigation in snakes (Holding et al., 2012; Roth et al., 2006). LaDage et al. (2009) observed higher dorsal cortex volume in male side-blotched lizards (Uta stansburiana) that maintained larger territories compared to smaller territories. Similarly, Holding et al. (2012) observed a larger medial cortex volume with increased spatial demands in male northern Pacific rattlesnakes (Crotalus oreganus oreganus). While I did not directly measure volume size changes in the combined cortex in the current study, I speculate that increasing spatial demands during migration could increase regional volume by 
increasing the number of cells (e.g., more NPY-ir cells). However, this was not observed, as regional volume correlated with snake SVL. Alternatively, NPY in the cortex could be related to hypothalamus-pituitary-adrenal axis sensitivity. Specifically, a suppressed stress response in spring occurs only male red-sided garter snakes (C. Dayger, personal communication), which could be mediated via glucocorticoid receptors in the hypothalamus-pituitary-adrenal axis. This may explain why similar differences in NPY-ir cell number in the cortex of females are not seen during the same migratory period as males.

Future research will need to examine the location NPY within the cortex is being released to and which type of cells have receptors for NPY binding (e.g., anterograde and retrograde labeling of NPY cells or NPY receptor labeling), and which of the five NPY receptors (Y1-Y5) is activated by NPY release within the cortex. Each NPY receptor has a different effect on behavior. For example, Y2 receptors mediate lordosis duration, whereas Y1 and Y5 receptors mediate food intake and hoarding in Syrian Hamsters (Mesocricetus auratus; reviewed in Schneider et al., 2013). Knowing which NPY receptor type is activated in the cortex will give us a better understanding if NPY cells in the cortex are related to spatial memory, stress responses, or the more traditional function of NPY on feeding behavior.

Additionally, I observed significantly more NPY-ir cells in the PH of male snakes during the fall and a significant interaction between season and migratory status in the number of NPY-ir cells in the $\mathrm{PH}$ of females. The $\mathrm{PH}$ is important for regulation of feeding behavior (Chee and Colmers, 2008). To have a better understanding of the function of NPY in the PH, it will be important to examine which NPY receptors are 
being activated in the PH, as well as examining NPY-ir cell number at additional time points throughout the summer in both males and females. Specifically, examining the number of NPY-ir cells in migratory snakes that have transitioned to feeding behavior to compare to snakes at the summer feeding grounds will help understand if NPY-ir cell number increases during activation of feeding behavior or in response to feeding. This will help determine if NPY-ir cells are related to migration and initiation of feeding behavior, or potentially maintenance of feeding behavior once consumptive behavior has begun.

Sex Differences

I observed significantly more AVT-ir cells in the POA of females compared to males, but otherwise no other brain region had exhibited sexual differences. I was able to study the effects of migration without the confounding effects of reproductive status, however, I did not take into account when each snake had emerged from hibernation. It is possible that males suppress AVT production during the spring and reach female AVT-ir levels during the summer, and decrease again during the fall, but this is speculation that will need to be tested. More likely, AVT-ir cells in the POA of females during the spring could be related to a slightly earlier activation of summer gametogenesis compared to males and parturition prior to fall collection. Specifically, female snakes emerge from the den, undergo vitellogenesis, mate and migrate within a day (Shine et al., 2001), ovulate 6-8 wks after mating, and give birth 6 wks thereafter (Whittier et al., 1987; Garstka et al., 1985; Gregory, 1977). In males, reproductive activity following migration to summer 
feeding grounds is limited to spermatogenesis. Future studies will need to sample male and female snakes over a time course following emergence to characterize the change in AVT-ir cells within the POA throughout these reproductive stages.

Future studies will need to examine the function of AVT in the POA of females compared to males. Additionally, future studies should examine if there are sex differences during a transition from non-feeding to feeding behavior due to the sex difference in timing. These studies, along with the current research, will provide an overall scope of how AVT and NPY play a role in independently deactivating courtship behavior and activating feeding behavior within males and females.

\section{Changes in Migratory Status}

I did not observe any significant main effects of migratory status in any of the brain regions examined within either males or females. However, I observed a potential trend for a main effect of migratory status on AVT-ir cell number within the SON of males $(\mathrm{p}=0.10)$. This relationship should be further examined as it is likely related to increased terrestrial activity during migration. Perhaps analysis of AVT-ir cell number at consecutive time points following emergence will extract more information about how migration, and associated stressors, relates to a change in reproductive status and behavior (i.e., because I observed more AVT-ir cells in the SON of non-courting males compared to courting males). Alternatively, perhaps I did not observe a main effect of migratory status because I held the snakes for 4 days following BrdU treatment before tissue sampling, with decreased osmotic stress as all snakes were provided water ad 
libitum. However, Maine et al. (2014) did not observe a significant difference in BrdU-ir cell numbers between 1 and 4 days after initial capture, but future studies will need to address changes in AVT-ir cell number following 4 days of capture.

Within the BNST of males, AVT-ir cell number was greater during the spring compared to the fall and I observed a significant interaction between season and migratory status. Not only is the BNST important for reproductive behavior (Ball and Balthazart, 2011), it also plays an important role in the vomeronasal system by providing chemosensory information about nearby food and conspecific pheromones to the hypothalamus from the NS and accessory olfactory bulb (Martinez-Marcos et al., 2005). Additionally, Lutterschmidt and Maine (2014) observed a higher number of NPY-ir cells within the NS of male red-sided garter snakes with increased feeding behavior. Taken together, it is likely that AVT-ir cells within the BNST of males are important for mediating a transition to feeding behavior during the spring. However, future studies will need to examine retrograde labeling of AVT cells in the BNST and NPY cells in the NS to determine where these neurons are projecting to, and if they are interrelated to the vomeronasal/olfactory system. Additionally, future studies should examine if migratory status during the spring and fall relates to changes in AVT, NPY, and the vomeronasal/olfactory system, which will likely provide more details as to why season and migratory status are linked within the BNST of male snakes.

Within the SON of females, I observed a significant interaction between season and migratory status because AVT-ir cell number was greater during the fall compared to the spring at females collected at the den ( $p=0.01$; Tukey's multiple comparisons test). Similarly, I observed a greater number of AVT-ir cells in the SON of male snakes during 
the fall. As previously discussed, the SON is likely related to maintaining water balance. While I did not observe a main effect of season in females, I would predict that females returning to the den in the fall have expended more energy (i.e., giving birth), and under larger osmotic stress than females emerging from winter dormancy, with a dampened metabolism, but this hypothesis has not been tested. This would be a similar trend to the potential osmotic stress males undergo between spring and fall. Within females, I also observed a significant interaction between season and migratory status in the number of NPY-ir cells in the PH. Perhaps a larger sample size of female snakes collected at the road during the fall will help to clarify any potential differences in NPY-ir cell number within the $\mathrm{PH}$, as these data appear to have a similar trend as observed in male $\mathrm{PH}$.

The current study was developed from previous research by Lutterschmidt and Maine (2014), in which the authors examined changes in AVT- and NPY-ir cell number in response to an induced increase in feeding behavior during the spring in red-sided garter snakes. We did not observe any differences in AVT-ir cell number in any brain region, but we did observe a greater number of NPY cells in both the cortex and NS with an increase in feeding behavior. My current study observed significantly more AVT-ir cells in the SON with the cessation of courtship behavior in male snakes and more NPYir cells in the cortex and PH following summer feeding. Future research needs to examine AVT-ir cell number with the activation of feeding behavior during the spring, as well as when NPY-ir cell number increases with increased feeding behavior during migration or at the feeding grounds. Anecdotally, within males collected at the road I observed a combination of courting/non-courting with feeding/non-feeding behavior. Because courtship and feeding behaviors are not mutually exclusive, as suggested by 
Lutterschmidt and Maine, 2014, future research will need to examine each of these behavior combinations to better understand how the transition from courtship to feeding behavior is activated.

Changes in Reproductive Status

I observed marginally more AVT-ir cells in the POA $(p=0.057)$ and significantly more NPY-ir cells in the cortex of non-courting males compared to courting males. The AH-POA is important for the initiation and maintenance of reproductive behavior and contain sex steroid-concentrating neurons (Krohmer and Crews, 1987a,b; Halpern et al., 1982). While non-courting males did not court, it is possible that if given a choice between a female pheromone trail or worm trail, some non-courting male snakes would choose a female trail. Indeed, as mentioned earlier, male snakes collected at the road have a combination of non-courting with non-feeding or feeding behavior (e.g., worm trail choice). Perhaps AVT-ir cells within the POA of non-courting males are still mediating courtship behavior and NPY-ir cells within the cortex are inhibiting courtship behavior, further suggesting that these behaviors are not mutually exclusive but future studies will need to address these hypotheses.

\section{Comparisons between Thamnophis Populations}

Red-sided garter snakes (T. sirtalis parietalis) are a wonderful model system for obtaining a basic understanding of life-history transitions in behavior. Because they must 
prioritize behaviors on a short time scale, I are able to study seasonal transitions between life-history stages of hibernation, reproduction, migration and foraging. However, to gain a better understanding of how animals respond to different cycles of life-history stages, future studies must address the same questions in this study within the same species experiencing different environments. The genus Thamnophis is ideal for future studies, as there are numerous other populations of Thamnophis sirtalis. In addition to this current work, two additional populations can be examined which inhabit different environments than Manitoba, Canada: Red-spotted garter snakes (T. sirtalis concinnus) in western Oregon and a population of Eastern garter snakes (T. sirtalis sirtalis), in southern Florida. These different populations have very different life-history cycles, due to the different climate and temperature profiles each population experiences. Future studies can use these populations to examine transitions in behavior on longer time-scales.

\section{Conclusion}

Collectively, this work is important for understanding the role that AVT and NPY play during life-history transitions. I observed regional differences within the brain, differences between sexes and season, as well as reproductive status. While I did not observe a main effect of migratory status, I did observe significant interactions between season and migratory status in three brain regions, suggesting that migratory status is playing a more complex role during life-history transitions. This work laid the groundwork for understanding how neuropeptides are mediating a transition between reproduction, migration, and foraging. However, there is still much research that needs to 
be conducted to gain an understanding of how neuropeptides are regulating transitions in physiology and behavior. My work will shape future adventures in the complex and interrelated world of neurobiology. 
Table 1. Sample sizes of male and female red-sided garter snakes (Thamnophis sirtalis parietalis) collected during the spring and fall. Snakes were collected in different migratory (Exp. 1) and reproductive (Exp. 2) states. Arrows reflect the migration of snakes over time, from the den to the road during the spring and from the road back to the den during the fall.

\begin{tabular}{|c|c|c|c|c|}
\hline & \multicolumn{2}{|l|}{ Spring } & \multicolumn{2}{|l|}{ Fall } \\
\hline \multirow{3}{*}{$\begin{array}{l}\text { Exp. 1: } \\
\text { Season, Sex } \\
\text { and } \\
\text { Migration }\end{array}$} & $\begin{array}{l}\text { Den } \\
\text { (pre-migratory) }\end{array}$ & $\rightarrow \begin{array}{l}\text { Road } \\
\text { (migratory) }\end{array}$ & $\begin{array}{l}\text { Road } \\
\text { (migratory) }\end{array}$ & $\rightarrow \begin{array}{ll}\text { Den } \\
\text { (post-migratory) }\end{array}$ \\
\hline & 10 courting $\delta^{\lambda}$ & 10 courting $\sigma^{\lambda}$ & $10 \sigma^{\lambda}$ & $10 \sigma^{\lambda}$ \\
\hline & 11 mated ㅇ & 10 mated $P$ & 10 우 & 10 우 \\
\hline $\begin{array}{l}\text { Exp. 2: } \\
\text { Reproductive } \\
\text { Status }\end{array}$ & 10 unmated $q$ & 12 non-courtir & & \\
\hline
\end{tabular}




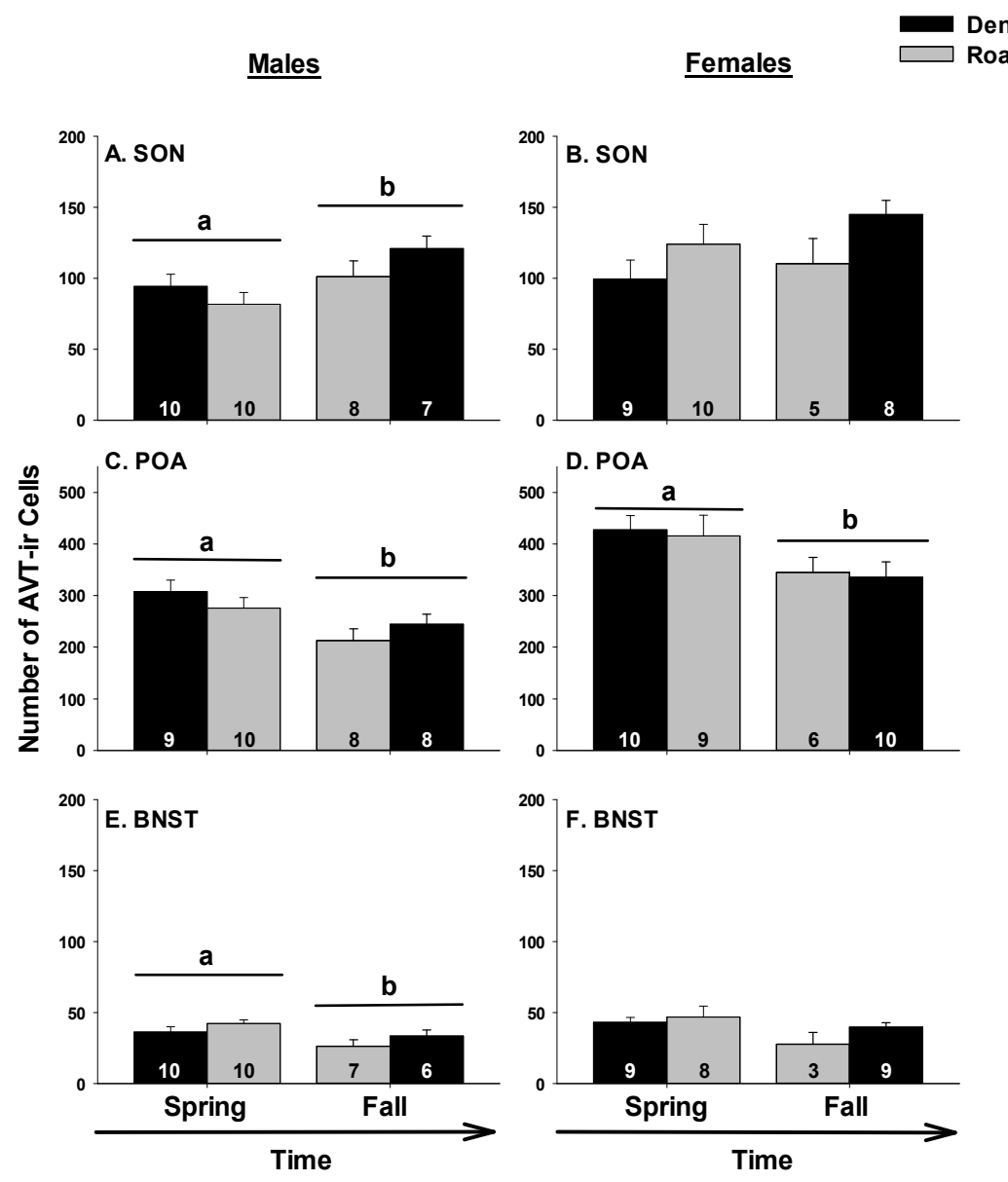

Figure 1

Figure 1. Effects of season and migratory status on the total number of AVT-ir cells in the (A, B) supraoptic nucleus $(\mathrm{SON}),(\mathrm{C}, \mathrm{D})$ preoptic area $(\mathrm{POA})$, and $(\mathrm{E}, \mathrm{F})$ bed nucleus of the stria terminalis (BNST) of male and female red-sided garter snakes (Thamnophis sirtalis parietalis), respectively. The $\mathrm{x}-$ axis is arranged to reflect the migration of snakes over time, from the den to the feeding grounds during the spring and from the feeding grounds back to the den during the fall. In both seasons, I intercepted migratory snakes on a road located approximately $0.9 \mathrm{~km}$ from the den site. Thus, collection of snakes at the den and road represent differences in the migratory status of snakes. Each bar is the mean number of AVT-labeled cells + 1 SEM. Lowercase letters indicate significant differences between seasons in male snakes (statistics from two-way ANOVAs). Final sample sizes within each region of interest are shown above the $\mathrm{x}$-axes. 
$\underline{\text { Males }}$
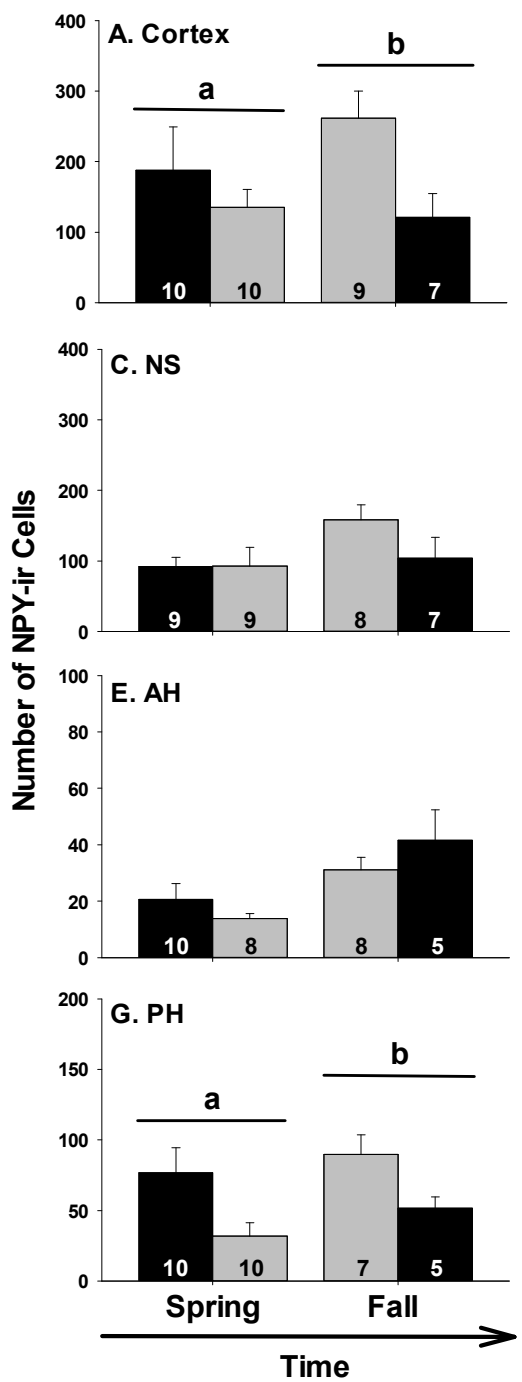

Females
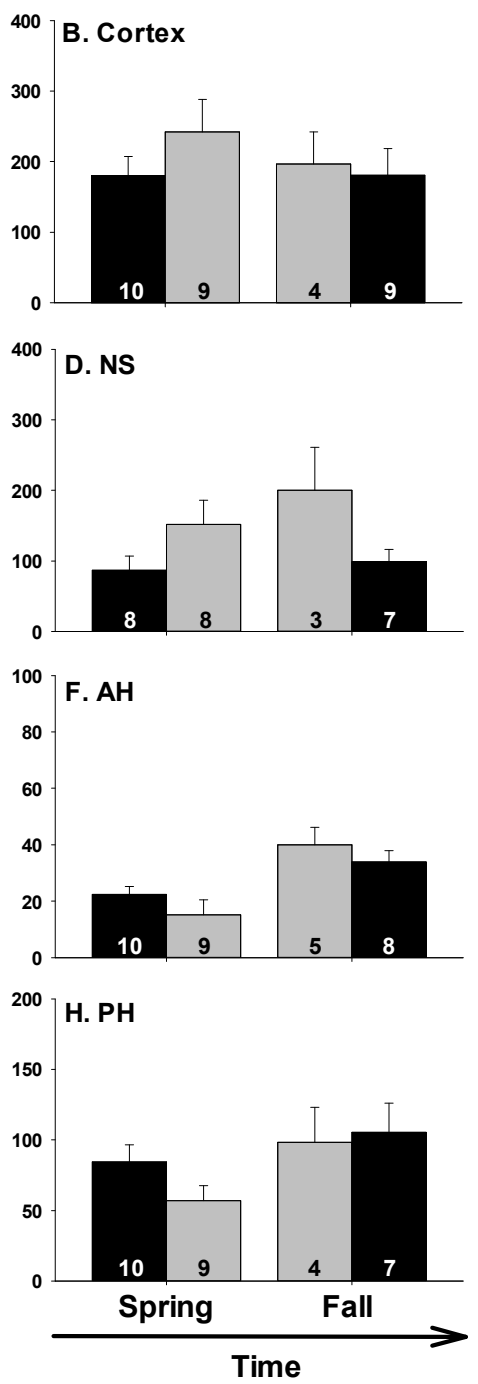

Figure 2

Figure 2. Effects of season and migratory status on the total number of NPY-ir cells in the (A, B) cortex, $(\mathrm{C}, \mathrm{D})$ nucleus sphericus $(\mathrm{NS}),(\mathrm{E}, \mathrm{F})$ anterior hypothalamus $(\mathrm{AH})$ and $(\mathrm{G}, \mathrm{H})$ posterior hypothalamus $(\mathrm{PH})$ of male and female red-sided garter snakes (Thamnophis sirtalis parietalis), respectively. The $\mathrm{x}$-axis is arranged to reflect the migration of snakes over time, from the den to the feeding grounds during the spring and from the feeding grounds back to the den during the fall. In both seasons, I intercepted migratory snakes on a road located approximately $0.9 \mathrm{~km}$ from the den site. Thus, collection of snakes at the den and road represent differences in the migratory status of snakes. Each bar is the mean number of NPY-labeled cells +1 SEM. Lowercase letters indicate significant differences between seasons in male snakes (statistics from two-way ANOVAs). Final sample sizes within each region of interest are shown above the x-axes. 


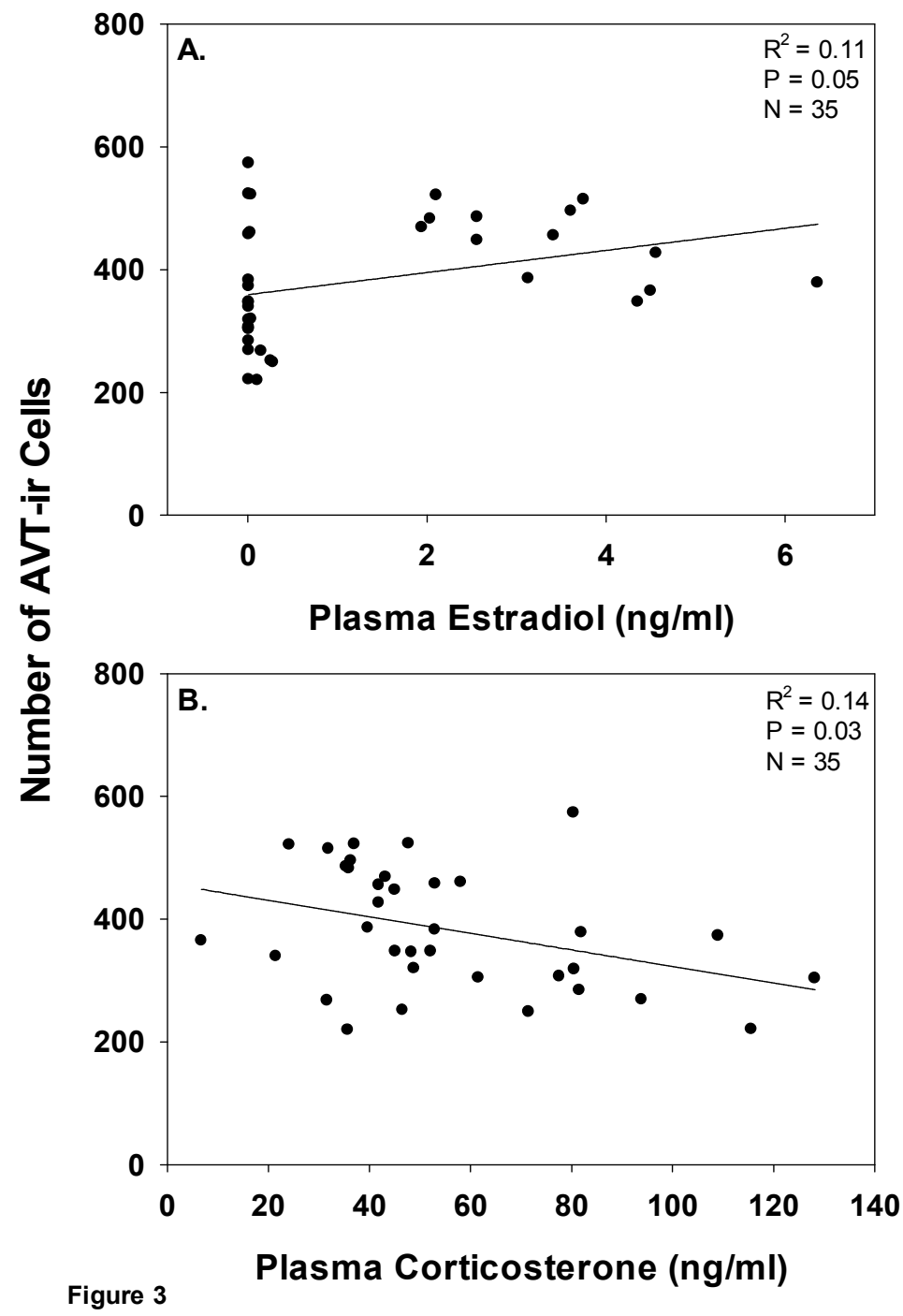

Figure 3. Relationship between the number of AVT-ir cells within the preoptic area (POA) and (A) plasma estradiol and (B) plasma corticosterone concentrations within female red-sided garter snakes (Thamnophis sirtalis parietalis) in experiment 1 . Statistics in the upper right corner of each figure are from linear regressions. 
$\underline{\text { Males }}$
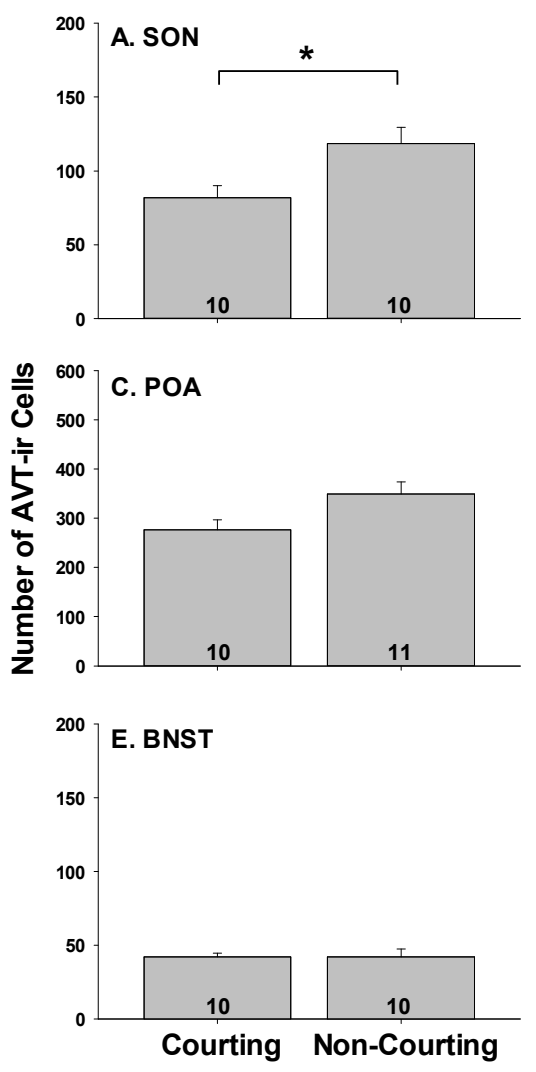

Females
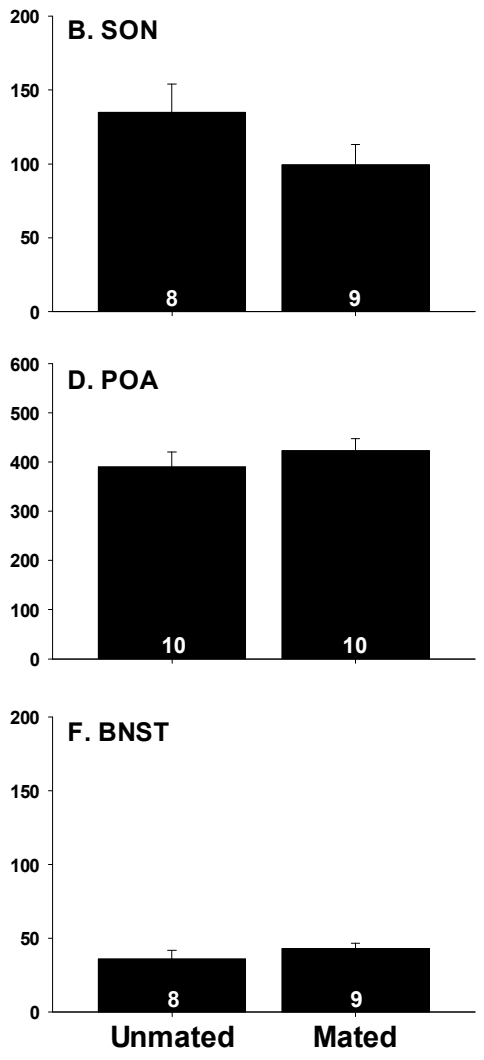

Figure 4

Figure 4. Effects of reproductive status on the total number of AVT-ir cells in male and female red-sided garter snakes (Thamnophis sirtalis parietalis) within the (A, B) supraoptic nucleus (SON), (C, D) preoptic area (POA), and (E, F) bed nucleus of the stria terminalis (BNST). Male snakes were collected during migration from a road located approximately $0.9 \mathrm{~km}$ from the den site; behavioral trials were used to assess courtship behavior and categorize snakes as courting or non-courting (grey bars). Unmated and mated female snakes were collected from the den (black bars). Thus, within each sex, snakes were collected from the same location, allowing us to assess differences related specifically to reproductive status. Each bar is the mean number of AVT-labeled cells + 1 SEM. Asterisk indicates a significant difference in AVT-ir cell number between courting and non-courting males in the SON (from a t-test). Final sample sizes within each region of interest are shown above the $\mathrm{x}$-axes. 
Males
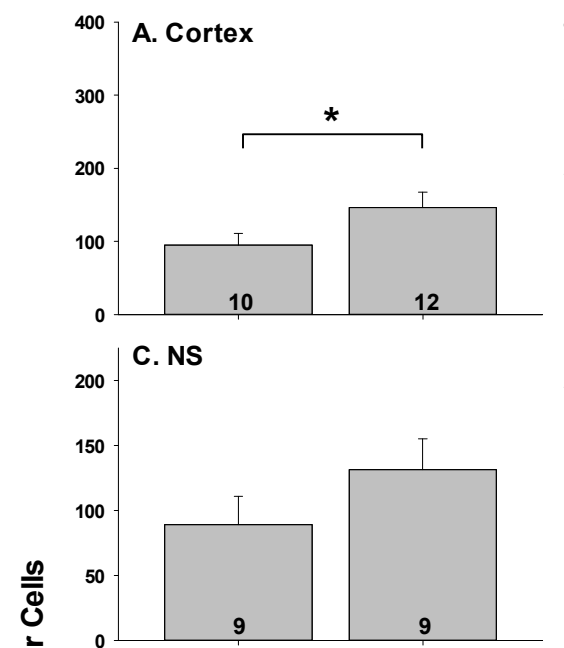

京

范
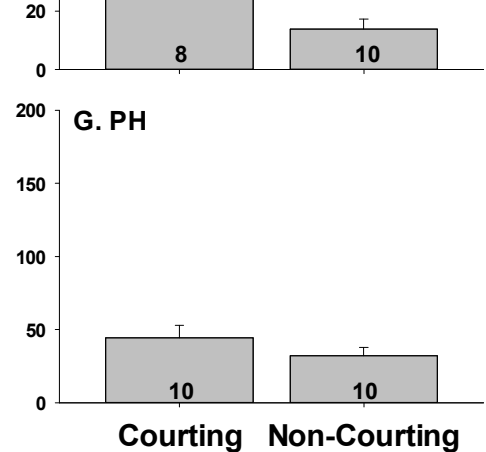

(B)

B. Cortex

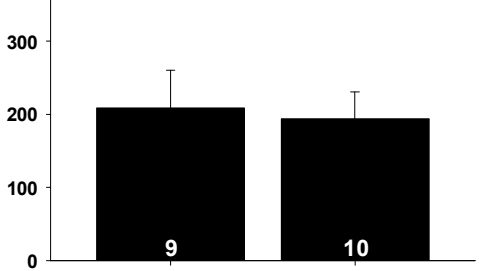

D. NS
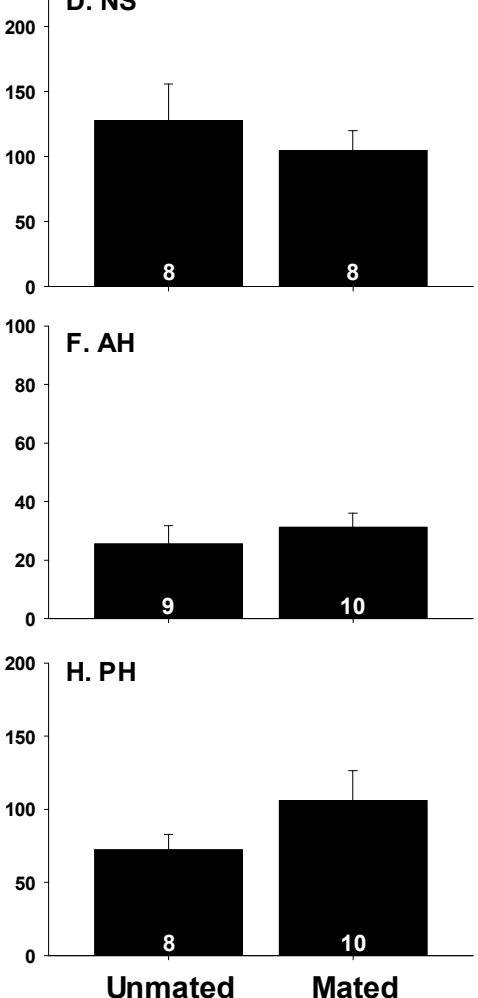

Figure 5

Figure 5. Effects of reproductive status on the total number of NPY-ir cells in male and female red-sided garter snakes (Thamnophis sirtalis parietalis) within the (A, B) cortex, (C, D) nucleus sphericus (NS), (E, $\mathrm{F})$ anterior hypothalamus $(\mathrm{AH})$ and $(\mathrm{G}, \mathrm{H})$ posterior hypothalamus $(\mathrm{PH})$. Male snakes were collected during migration from a road located approximately $0.9 \mathrm{~km}$ from the den site; behavioral trials were used to assess courtship behavior and categorize snakes as courting or non-courting (grey bars). Unmated and mated female snakes were collected from the den (black bars). Thus, within each sex, snakes were collected from the same location, allowing us to assess differences related specifically to reproductive status. Each bar is the mean number of NPY-labeled cells +1 SEM. Asterisk indicates a significant difference in NPYir cell number between courting and non-courting males in the cortex (from a t-test). Final sample sizes within each region of interest are shown above the $\mathrm{x}$-axes. 


\section{References:}

Aldegunde, M., Mancebo, M., 2006. Effects of neuropeptide Y on food intake and brain biogenic amines in the rainbow trout (Oncorhynchus mykiss). Peptides 27, 719727.

Almli, L.M., Wilczynski, W., 2007. Regional distribution and migration of proliferating cell populations in the adult brain of Hyla cinerea (Anura, Amphibia). Brain Res. 1159, 112-118.

Babichuk, N.A., Volkoff, H., 2013. Changes in expression of appetite-regulating hormones in the cunner (Tautogolabrus adspersus) during short-term fasting and winter torpor. Physiol. Behav. 120, 54-63.

Ball, G.F., Balthazart, J., 2011. Sexual arousal, is it for mammals only? Horm. Behav., Special Issue on Research on Sexual Arousal 59, 645-655.

Ball, G.F., Ketterson, E.D., 2008. Sex differences in the response to environmental cues regulating seasonal reproduction in birds. Philos. Trans. R. Soc. B Biol. Sci. 363, 231-246.

Barnea, A., Nottebohm, F., 1994. Seasonal recruitment of hippocampal neurons in adult free-ranging black-capped chickadees. Proc. Natl. Acad. Sci. U. S. A. 91, $11217-$ 11221.

Beery, A.K., Trumbull, J. J, Tsao, J. M, Costantini, R. M, Zucker, I, 2007. Sex differences in the onset of seasonal reproductive quiescence in hamsters. Proc. R. Soc. B Biol. Sci. Proc. R. Soc. B Biol. Sci. 274, 281-286.

Bojkowska K, H.M., Tsai HW, Riggan A, Rissman EF, 2008. Neuropeptide Y influences acute food intake and energy status affects NPY immunoreactivity in the female musk shrew (Suncus murinus). Horm. Behav. 53, 342-50.

Boyd, S.K., 1994. Arginine vasotocin facilitation of advertisement calling and call phonotaxis in bullfrogs. Horm. Behav. 28, 232-240.

Boyd, S.K., 1991. Effect of vasotocin on locomotor activity in bullfrogs varies with developmental stage and sex. Horm. Behav. 25, 57-69.

Boyko, A.R., Gibson, R.M., Lucas, J.R., 2004. How predation risk affects the temporal dynamics of avian leks: Greater Sage Grouse versus Golden Eagles. Am. Nat. $163,154-165$.

Bryan HM, D.C., Paquet PC, Wynne-Edwards KE, Smits JE, 2013. Stress and reproductive hormones in grizzly bears reflect nutritional benefits and social consequences of a salmon foraging niche. PloS One 8.

Burbach, J.P.H., 2011. What are neuropeptides? Methods Mol. Biol. Clifton NJ 789, 136.

Butler, A.B., Hodos, W., 1996. Comparative Vertebrate Neuroanatomy: Evolution and Adaptation. John Wiley \& Sons.

Caldwell, J.D., Drago, F., Prange, A.J., Pedersen, C.A., 1986. A comparison of grooming behavior potencies of neurohypophyseal nonapeptides. Regul. Pept. 14, 261-271.

Cease, A.J., Lutterschmidt, D.I., Mason, R.T., 2007. Corticosterone and the transition from courtship behavior to dispersal in male red-sided garter snakes (Thamnophis sirtalis parietalis). Gen. Comp. Endocrinol. 150, 124-131. 
Chee, M.J.S., Colmers, W.F., 2008. Y eat? Nutr. Burbank Los Angel. Cty. Calif 24, 869877.

Clark, J.T., Kalra, P.S., and Kalra, S.P. (1997). Neuropeptide Y stimulates feeding but inhibits sexual behavior in rats. 1985. Obes. Res. 5, 275-283.

Cooper, N.W., Murphy, M.T., Redmond, L.J., 2009. Age- and sex-dependent spring arrival dates of Eastern Kingbirds. J. Field Ornith. 80, 35-41.

Corp, E.S., Gréco, B., Powers, J.B., Bivens, C.L.M., and Wade, G.N. (2001). Neuropeptide $\mathrm{Y}$ inhibits estrous behavior and stimulates feeding via separate receptors in Syrian hamsters. Am. J. Physiol. - Regul. Integr. Comp. Physiol. 280, R1061-R1068.

Crews, D., 1984. Gamete production, sex hormone secretion, and mating behavior uncoupled. Horm. Behav. 18, 22-28.

Crews, D., Robker, R., Mendonca, M., 1993. Seasonal fluctuations in brain nuclei in the red-sided garter snake and their hormonal control. J. Neurosci. 13, 5356-5364.

Danger, J.M., Tonon, M.C., Jenks, B.G., Saint-Pierre, S., Martel, J.C., Fasolo, A., Breton, B., Quirion, R., Pelletier, G., Vaudry, H., 1990. Neuropeptide Y: localization in the central nervous system and neuroendocrine functions. Fundam. Clin. Pharmacol. 4, 307-340.

Dawson, A., 2005. The effect of temperature on photoperiodically regulated gonadal maturation, regression and moult in starlings - potential consequences of climate change. Funct. Ecol. 19, 995-1000.

De Vries, G.J., Boyle, P.A., 1998. Double duty for sex differences in the brain. Behav. Brain Res. 92, 205-213.

Dunham, L.A., Wilczynski, W., 2014. Arginine vasotocin, steroid hormones and social behavior in the green anole lizard (Anolis carolinensis). J. Exp. Biol. 217, 36703676.

Egawa M, Y.H., Bray GA, 1990. Effect of corticotropin releasing hormone and neuropeptide $\mathrm{Y}$ on electrophysiological activity of sympathetic nerves to interscapular brown adipose tissue. Neuroscience 34, 771-5.

Foran, C.M., Bass, A.H., 1999. Preoptic GnRH and AVT: Axes for Sexual Plasticity in Teleost Fish. Gen. Comp. Endocrinol. 116, 141-152.

Garstka, W.R., Tokarz, R.R., Diamond, M., Halpert, A., Crews, D., 1985. Behavioral and physiological control of yolk synthesis and deposition in the female red-sided garter snake (Thamnophis sirtalis parietalis). Horm. Behav. 19, 137-153.

Gehlert, D.R., 2004. Introduction to the reviews on neuropeptide Y. Neuropeptides, Special Issue on Neuropeptide Y 38, 135-140.

George, J.C., John, T.M., 1987. Seasonal immunocytochemical and ultrastructural changes in the neurohypophysis of the migratory Canada goose. Cytobios 49, 111-128.

Goodson, J.L., 2005. The Vertebrate Social Behavior Network: Evolutionary Themes and Variations. Horm. Behav. 48, 11-22.

Goodson, J.L., Bass, A.H., 2001. Social behavior functions and related anatomical characteristics of vasotocin/vasopressin systems in vertebrates. Brain Res. Rev. 35, 246-265.

Gregory, P.T., 1977. Life-history parameters of the red-sided garter snake (Thamnophis 
sirtalis parietalis) in an extreme environment, the Interlake Region of Manitoba. National Museums of Canada, Ottawa.

Gregory, P.T., Stewart, K.W., 1975. Long-distance dispersal and feeding strategy of the red-sided garter snake (Thamnophis sirtalis parietalis) in the Interlake of Manitoba. Can J Zool Can. J. Zool. 53, 238-245.

Guillette, L.J., Pfrimmer Hensley, A., Matter, J.M., Jaffe, P.H., 1990. Indomethacin influences arginine vasotocin-induced parturition and oviposition in lizards (Sceloporus jarrovi and Sceloporus undulatus). Theriogenology 33, 809-818.

Halpern, M., Morrell, J.I., Pfaff, D.W., 1982. Cellular [3H]estradiol and [3H]testosterone localization in the brains of garter snakes: an autoradiographic study. Gen. Comp. Endocrinol. 46, 211-224.

Heilig, M., Murison, R., 1987. Intracerebroventricular neuropeptide Y suppresses open field and home cage activity in the rat. Regul. Pept. 19, 221-231.

Heinrichs SC, C.B., Pich EM, Menzaghi F, Koob GF, Hauger RL, 1992. Endogenous corticotropin-releasing factor modulates feeding induced by neuropeptide $\mathrm{Y}$ or a tail-pinch stressor. Peptides 13.

Holding, M.L., Frazier, J.A., Taylor, E.N., Strand, C.R., 2012. Experimentally altered navigational demands induce changes in the cortical forebrain of free-ranging Northern Pacific Rattlesnakes (Crotalus o. oreganus). Brain. Behav. Evol. 79, 144-154.

Jonsson, B., Jonsson, N., 2009. A review of the likely effects of climate change on anadromous Atlantic salmon Salmo salar and brown trout Salmo trutta, with particular reference to water temperature and flow. J. Fish Biol. 75, 2381-2447.

Jonsson, N., Jonsson, B., Hansen, L.P., 1990. Partial segregation in the timing of migration of Atlantic salmon of different ages. Anim. Behav. 40, 313-321.

Kabelik, D., Alix, V.C., Burford, E.R., Singh, L.J., 2013. Aggression- and sex-induced neural activity across vasotocin populations in the brown anole. Horm. Behav. 63, 437-446.

Kabelik, D., Weiss, S.L., Moore, M.C., 2008. Arginine vasotocin (AVT) immunoreactivity relates to testosterone but not territorial aggression in the tree lizard, Urosaurus ornatus. Brain. Behav. Evol. 72, 283-294.

Kabelik, D., Weiss, S.L., Moore, M.C., 2006. Steroid hormone mediation of limbic brain plasticity and aggression in free-living tree lizards, Urosaurus ornatus. Horm. Behav. 49, 587-597.

Kovács, É.G., Szalay, F., Rácz, B., Halasy, K., 2007. Chronic fasting-induced changes of neuropeptide $\mathrm{Y}$ immunoreactivity in the lateral septum of intact and ovariectomized female rats. Brain Res. 1153, 103-110.

Krohmer, R.W., Boyle, M.H., Lutterschmidt, D.I., Mason, R.T., 2010. Seasonal aromatase activity in the brain of the male red-sided garter snake. Horm. Behav. 58, 485-492.

Krohmer, R.W., Crews, D., 1987a. Facilitation of courtship behavior in the male redsided garter snake (Thamnophis sirtalis parietalis) following lesions of the septum or nucleus sphericus. Physiol. Behav. 40, 759-765.

Krohmer, R.W., Crews, D., 1987b. Temperature activation of courtship behavior in the male red-sided garter snake (Thamnophis sirtalis parietalis): role of the anterior 
hypothalamus-preoptic area. Behav. Neurosci. 101, 228-236.

Krohmer, R.W., DeMarchi, G.A., Baleckaitis, D.D., Lutterschmidt, D.I., Mason, R.T., 2011. Brain nuclei in actively courting red-sided garter snakes: A paradigm of neural trimorphism. Physiol. Behav. 102, 532-537.

Laberge, F., Feldhoff, R.C., Feldhoff, P.W., Houck, L.D., 2008. Courtship pheromoneinduced c-Fos-like immunolabeling in the female salamander brain. Neuroscience 151, 329-339.

LaDage, L.D., Riggs, B.J., Sinervo, B., and Pravosudov, V.V. (2009). Dorsal cortex volume in male side-blotched lizards, Uta stansburiana, is associated with different space use strategies. Anim. Behav. 78, 91-96.

Landgraf, R., Neumann, I.D., 2004. Vasopressin and oxytocin release within the brain: a dynamic concept of multiple and variable modes of neuropeptide communication. Front. Neuroendocrinol. 25, 150-176.

Lanuza, E., Halpern, M., 1997. Afferent and efferent connections of the nucleus sphericus in the snake Thamnophis sirtalis: convergence of olfactory and vomeronasal information in the lateral cortex and the amygdala. J. Comp. Neurol. 385, 627-640.

Le Mevel, J.C., Mabin, D., Vaudry, H., 1991. Intracerebroventricular injection of arginine vasotocin induces elevation of blood pressure in anesthetized trout. Peptides 12, 477-481.

Levine, A.S., Morley, J.E., 1984. Neuropeptide Y: a potent inducer of consummatory behavior in rats. Peptides 5, 1025-1029.

Lim, M.M., Hammock, E. a. D., Young, L.J., 2004. The role of vasopressin in the genetic and neural regulation of monogamy. J. Neuroendocrinol. 16, 325-332.

Ludwig, M., Williams, K., Callahan, M.F., Morris, M., 1996. Salt loading abolishes osmotically stimulated vasopressin release within the supraoptic nucleus. Neurosci. Lett. 215, 1-4.

Lutterschmidt, D.I., LeMaster, M.P., Mason, R.T., 2004. Effects of melatonin on the behavioral and hormonal responses of red-sided garter snakes (Thamnophis sirtalis parietalis) to exogenous corticosterone. Horm. Behav. 46, 692-702.

Lutterschmidt, D.I., Maine, A.R., 2014. Sex or candy? Neuroendocrine regulation of the seasonal transition from courtship to feeding behavior in male red-sided garter snakes (Thamnophis sirtalis parietalis). Horm. Behav. 66(1):120-34.

Lutterschmidt, D.I., Mason, R.T., 2009. Endocrine mechanisms mediating temperatureinduced reproductive behavior in red-sided garter snakes (Thamnophis sirtalis parietalis). J. Exp. Biol. 212, 3108-3118.

Lutterschmidt, D.I., Mason, R.T., 2005. A serotonin receptor antagonist, but not melatonin, modulates hormonal responses to capture stress in two populations of garter snakes (Thamnophis sirtalis parietalis and Thamnophis sirtalis concinnus). Gen. Comp. Endocrinol. 141, 259-270.

Lutterschmidt, D.I., Wilczynski, W., 2012. Sexually dimorphic effects of melatonin on brain arginine vasotocin immunoreactivity in green treefrogs (Hyla cinerea). Brain. Behav. Evol. 80, 222-232.

MacDonald, E., Volkoff, H., 2009. Cloning, distribution and effects of season and nutritional status on the expression of neuropeptide Y (NPY), cocaine and 
amphetamine regulated transcript (CART) and cholecystokinin (CCK) in winter flounder (Pseudopleuronectes americanus). Horm. Behav. 56, 58-65.

Madison, F.N., Jurkevich, A., Kuenzel, W.J., 2008. Sex differences in plasma corticosterone release in undisturbed chickens (Gallus gallus) in response to arginine vasotocin and corticotropin releasing hormone. Gen. Comp. Endocrinol. $155,566-573$.

Maine, A.R., Powers, S.D., Lutterschmidt, D.I., 2014. Seasonal variation in cell proliferation and cell migration in the brain of adult red-sided garter snakes (Thamnophis sirtalis parietalis). Brain. Behav. Evol. 84(3):181-96.

Malva, J.., Xapelli, S., Baptista, S., Valero, J., Agasse, F., Ferreira, R., Silva, A.., 2012. Multifaces of neuropeptide $\mathrm{Y}$ in the brain - Neuroprotection, neurogenesis and neuroinflammation. Neuropept. 46, 299-308.

Maniam, J., Morris, M.J., 2012. The link between stress and feeding behaviour. Neuropharmacology 63, 97-110.

Marler, C.A., Chu, J., Wilczynski, W., 1995. Arginine vasotocin injection increases probability of calling in cricket frogs, but causes call changes characteristic of less aggressive Males. Horm. Behav. 29, 554-570.

Martínez-Marcos, A., Ubeda-Bañón, I., Halpern, M., 2001. Neural substrates for tongueflicking behavior in snakes. J. Comp. Neurol. 432, 75-87.

Martinez-Marcos, A., Ubeda-Bañon, I., Lanuza, E., Halpern, M., 2005. Efferent connections of the "olfactostriatum": a specialized vomeronasal structure within the basal ganglia of snakes. J. Chem. Neuroanat. 29, 217-226.

Martins, R.C., Catry, T., Santos, C.D., Palmeirim, J.M., Granadeiro, J.P., 2013. Seasonal variations in the diet and foraging behaviour of dunlins Calidris alpina in a south european estuary: Improved feeding conditions for northward migrants. PLoS ONE 8.

Maruska, K.P., Mizobe, M.H., Tricas, T.C., 2007. Sex and seasonal co-variation of arginine vasotocin (AVT) and gonadotropin-releasing hormone $(\mathrm{GnRH})$ neurons in the brain of the halfspotted goby. Comp. Biochem. Physiol. A. Mol. Integr. Physiol. 147, 129-144.

Matsuda K, K.K., Shimakura S, Miura T, Uchiyama M, Shioda S, Ando H, Takahashi A, 2009. Relationship between melanin-concentrating hormone- and neuropeptide Ycontaining neurons in the goldfish hypothalamus. Comp. Biochem. Physiol. A. Mol. Integr. Physiol. 153, 3-7.

McBride, J.R., Fagerlund, U.H.M., Smith, M., Tomlinson, N., 1965. Post-spawning death of Pacific salmon: Sockeye salmon (Oncorhynchus nerka) maturing and spawning in captivity. J Fish Res Bd Can J. Fish. Board Can. 22, 775-782.

McShane, T.M., May, T., Miner, J.L., Keisler, D.H., 1992. Central actions of neuropeptide-Y may provide a neuromodulatory link between nutrition and reproduction. Biol. Reprod. 46, 1151-1157.

Mendonça, R., Soares, M.C., Bshary, R., Oliveira, R.F., 2013. Arginine vasotocin neuronal phenotype and interspecific cooperative behaviour. Brain. Behav. Evol. 82, 166-176.

Mercer, R.E., Chee, M.J.S., Colmers, W.F., 2011. The role of NPY in hypothalamic mediated food intake. Front. Neuroendocrinol. 32, 398-415. 
Migaud, M., Batailler, M., Pillon, D., Franceschini, I., Malpaux, B., 2011. Seasonal changes in cell proliferation in the adult sheep brain and pars tuberalis. J. Biol. Rhythms 26, 486-496.

Moore, F.L., Miller, L.J., 1983. Arginine vasotocin induces sexual behavior of newts by acting on cells in the brain. Peptides 4, 97-102.

Moore, I., Lemaster, M.P., Mason, R., 2000. Behavioural and hormonal responses to capture stress in the male red-sided garter snake, Thamnophis sirtalis parietalis. Anim. Behav. 59, 529-534.

Moreines, J.K., Powers, J.B., 1977. Effects of acute ovariectomy on the lordosis response of female rats. Physiol. Behav. 19, 277-283.

Morris, Y.A., Crews, D., 1990. The effects of exogenous neuropeptide Y on feeding and sexual behavior in the red-sided garter snake (Thamnophis sirtalis parietalis). Brain Res. 530, 339-341.

O’Donnell, R.P., Shine, R., Mason, Robert T, 2004. Seasonal anorexia in the male redsided garter snake, Thamnophis sirtalis parietalis. Behav Ecol Sociobiol Behav. Ecol. Sociobiol. 56, 413-419.

Post, E., Forchhammer, M.C., 2008. Climate change reduces reproductive success of an Arctic herbivore through trophic mismatch. Philos. Trans. R. Soc. B Biol. Sci. 363, 2369-2375.

Powers, J.G., Baker, D.L., Davis, T.L., Conner, M.M., Lothridge, A.H., Nett, T.M., 2011. Effects of gonadotropin-releasing hormone immunization on reproductive function and behavior in captive female Rocky Mountain Elk (Cervus elaphus nelsoni) 1. Bire Biol. Reprod. 85, 1152-1160.

Reudink, M.W., Marra, P.P., Kyser, T.K., Boag, P.T., Langin, K.M., Ratcliffe, L.M., 2009. Non-breeding season events influence sexual selection in a long-distance migratory bird. Proc. Biol. Sci. 276, 1619-1626.

Roth, E.D., Lutterschmidt, W.I., Wilson, D.A., 2006. Relative medial and dorsal cortex volume in relation to sex differences in spatial ecology of a snake population. Brain. Behav. Evol. 67, 103-110.

Sahu, A., 2002. Interactions of neuropeptide Y, hypocretin-I (orexin A) and melaninconcentrating hormone on feeding in rats. Brain Res. 944, 232-238.

Sahu, A., Kalra, P.S., Kalra, S.P., 1988. Food deprivation and ingestion induce reciprocal changes in neuropeptide $Y$ concentrations in the paraventricular nucleus. Peptides 9, 83-86.

Salek, S.J., Sullivan, C.V., Godwin, J., 2002. Arginine vasotocin effects on courtship behavior in male white perch (Morone americana). Behav. Brain Res. 133, 177183.

Salom, S., Font, C., Martínez-García, F., 1994. Seasonal sexually dimorphic distribution of neuropeptide Y-like immunoreactive neurons in the forebrain of the lizard Podarcis hispanica. J. Chem. Neuroanat. 7, 217-225.

Schneider, J.E., 2004. Energy balance and reproduction. Physiol. Behav. 81, 289-317.

Schneider, J.E., Wise, J.D., Benton, N.A., Brozek, J.M., Keen-Rhinehart, E., 2013. When do we eat? Ingestive behavior, survival, and reproductive success. Horm. Behav. 64, 702-728.

Shimizu, S., Azuma, M., Morimoto, N., Kikuyama, S., Matsuda, K., 2013. Effect of 
neuropeptide $\mathrm{Y}$ on food intake in bullfrog larvae. Peptides 46, 102-107.

Shine, R., Elphick, M.J., Harlow, P.S., Moore, I.T., LeMaster, M.P., Mason, R.T., Price, A.H., 2001. Movements, mating, and dispersal of red-sided gartersnakes (Thamnophis sirtalis parietalis) from a communal den in Manitoba. Copeia 2001, 82-91.

Skoglund, H., Einum, S., Robertsen, G., 2011. Competitive interactions shape offspring performance in relation to seasonal timing of emergence in Atlantic salmon. J. Anim. Ecol. 80, 365-374.

Soares, M.C., Bshary, R., Mendonca, R., Grutter, A.S., Oliveira, R.F., 2012. Arginine vasotocin regulation of interspecific cooperative behaviour in a cleaner fish. PLoS ONE 7.

Tachibana, T., Saito, E.-S., Saito, S., Tomonaga, S., Denbow, D.M., Furuse, M., 2004. Comparison of brain arginine-vasotocin and corticotrophin-releasing factor for physiological responses in chicks. Neurosci. Lett. 360, 165-169.

Tatemoto, K., Carlquist, M., Mutt, V., 1982. Neuropeptide Y--a novel brain peptide with structural similarities to peptide YY and pancreatic polypeptide. Nature 296, 659660 .

Tito, M.B., Hoover, M.A., Mingo, A.M., Boyd, S.K., 1999. Vasotocin maintains multiple call types in the gray treefrog, Hyla versicolor. Horm. Behav. 36, 166-175.

Toyoda, F., Yamamoto, K., Ito, Y., Tanaka, S., Yamashita, M., Kikuyama, S., 2003. Involvement of arginine vasotocin in reproductive events in the male newt Cynops pyrrhogaster. Horm. Behav. 44, 346-353.

Visser, M.E., Holleman, L.J.M., Gienapp, P., 2006. Shifts in caterpillar biomass phenology due to climate change and its impact on the breeding biology of an insectivorous bird. Oecologia 147, 164-172.

Visser, M.E., Noordwijk, A.J. van, Tinbergen, J.M., Lessells, C.M., 1998. Warmer springs lead to mistimed reproduction in great tits (Parus major). Proc. R. Soc. Lond. B Biol. Sci. 265, 1867-1870.

Wada, H., 2008. Glucocorticoids: Mediators of vertebrate ontogenetic transitions. Gen. Comp. Endocrinol. 156, 441-453.

Whittier, J.M., Mason, R.T., Crews, D., 1987. Plasma steroid hormone levels of female red-sided garter snakes, Thamnophis sirtalis parietalis: relationship to mating and gestation. Gen. Comp. Endocrinol. 67, 33-43.

Wilczynski, W., Lynch, K.S., O’Bryant, E.L., 2005. Current research in amphibians: Studies integrating endocrinology, behavior, and neurobiology. Horm. Behav. 48, 440-450.

Wilson, M.F., 1993. Mammals as seed-dispersal mutualists in North America. OIKOS Cph.- 67, 159.

Wingfield, J.C., 2008. Comparative endocrinology, environment and global change. Gen. Comp. Endocrinol. 157, 207-216.

Wingfield, J.C., Farner, D.S., 1978. The endocrinology of a natural breeding population of the White-crowned Sparrow (Zonotrichia leucophrys pugetensis). Physiol. Zool. 51, 188-205.

Wingfield, J.C., Maney, D.L., Breuner, C.W., Jacobs, J.D., Lynn, S., Ramenofsky, M., Richardson, R.D., 1998. Ecological bases of hormone-behavior interactions: 
The “emergency life history stage.” Integr Comp Biol Integr. Comp. Biol. 38, 191-206.

Wójcik-Gładysz, A., Polkowska, J., 2006. Neuropeptide Y--a neuromodulatory link between nutrition and reproduction at the central nervous system level. Reprod. Biol. 6 Suppl 2, 21-28.

Xie, J., Kuenzel, W.J., Anthony, N.B., Jurkevich, A., 2010. Subpallial and hypothalamic areas activated following sexual and agonistic encounters in male chickens. Physiol. Behav. 101, 344-359.

Yokobori, E., Azuma, M., Nishiguchi, R., Kang, K.S., Kamijo, M., Uchiyama, M., Matsuda, K., 2012. Neuropeptide Y stimulates food intake in the Zebrafish, Danio rerio. J. Neuroendocrinol. 24, 766-773.

Zambotti-Villela, L., Marinho, C.E., Alponti, R.F., Silveira, P.F., 2007. Hypothalamic activity during altered salt and water balance in the snake Bothrops jararaca. J. Comp. Physiol. B 178, 57-66. 